University of Wollongong

Research Online

Faculty of Engineering and Information

Faculty of Engineering and Information

Sciences - Papers: Part B

Sciences

2018

Influence of Steel Fibres on the Behaviour of RPC Circular Columns Under Different Loading Conditions

Ahmed Al-Tikrite

University of Wollongong, afs017@uowmail.edu.au

Muhammad N. S Hadi

University of Wollongong, mhadi@uow.edu.au

Follow this and additional works at: https://ro.uow.edu.au/eispapers1

Part of the Engineering Commons, and the Science and Technology Studies Commons

Research Online is the open access institutional repository for the University of Wollongong. For further information contact the UOW Library: research-pubs@uow.edu.au 


\title{
Influence of Steel Fibres on the Behaviour of RPC Circular Columns Under Different Loading Conditions
}

\author{
Abstract \\ An experimental program was conducted to investigate the effect of inclusion of steel fibres on the \\ behaviour of Reactive Powder Concrete (RPC) columns. Three different types of steel fibre were used: \\ micro straight steel fibre (MF), macro deformed steel fibre (DF) and waste steel fibre (WF) recovered from \\ discarded tyres. In addition, a hybridization of steel fibres was made up to produce waste-industrial \\ hybridization (WHF) (MF, DF and WF). Twenty reinforced RPC column specimens were prepared and \\ tested under axial concentric, eccentric and flexural loading. Results of testing demonstrated that the \\ ultimate axial load and the corresponding axial deformation increased effectively by the addition of steel \\ fibres, especially at the presence of MF. For the flexural loading, the inclusion of WF and WHF increased \\ the energy absorption of specimens by $470 \%$ and $453 \%$, respectively, in comparison with the \\ corresponding reference specimens. Axial load-bending moment (P-M) interaction diagrams were carried \\ out. Results of testing show that WF is a promising material for enhancing the behaviour of RPC under \\ different loading conditions.

\section{Disciplines} \\ Engineering | Science and Technology Studies

\section{Publication Details} \\ Al-Tikrite, A. \& Hadi, M. N. S. (2018). Influence of Steel Fibres on the Behaviour of RPC Circular Columns \\ Under Different Loading Conditions. Structures, 14 111-123.
}




\section{Influence of Steel Fibres on the behaviour of RPC Circular Columns under Different} Loading Conditions

Ahmed Al-Tikrite ${ }^{1}$

${ }^{1} \mathrm{PhD}$ Candidate, Structural Engineering, School of Civil, Mining and Environmental Engineering, University of Wollongong, Australia. Email: afs017@uowmail.edu.au Muhammad N. S. Hadi ${ }^{2}$

${ }^{2}$ Assoc. Professor, School of Civil, Mining and Environmental Engineering, University of Wollongong, Australia, Corresponding Author. Email: mhadi@uow.edu.au

\section{Abstract}

An experimental program was conducted to investigate the effect of inclusion of steel fibres on the behaviour of Reactive Powder Concrete (RPC) columns. Three different types of steel fibre were used: micro straight steel fibre (MF), macro deformed steel fibre (DF) and waste steel fibre (WF) recovered from discarded tyres. In addition, a hybridization of steel fibres was made up to produce waste-industrial hybridization (WHF) (MF, DF and WF). Twenty reinforced RPC column specimens were prepared and tested under axial concentric, eccentric and flexural loading. Results of testing demonstrated that the ultimate axial load and the corresponding axial deformation increased effectively by the addition of steel fibres, especially at the presence of MF. For the flexural loading, the inclusion of WF and WHF increased the energy absorption of specimens by $470 \%$ and $453 \%$, respectively, in comparison with the corresponding reference specimens. Axial load-bending moment $(P-M)$ interaction diagrams were carried out. Results of testing show that WF is a promising material for enhancing the behaviour of RPC under different loading conditions.

Keywords: RPC columns; Steel fibres; Load carrying capacity; Energy absorption; $P-M$ interactions. 


\section{Introduction}

Reactive Powder Concrete (RPC) is known as concrete with superior characteristics and is being increasingly used. The strength of RPC comes from the utilization of highly refined admixtures, low water to binder ratio and the exclusion of the course aggregate. The RPC is rated as a concrete with excellent strength and durability $[1,2]$. This type of concrete enables the designers to reduce the size of structural members such us columns in lower stories and consequently reduces the self-weight of the structure. However, RPC is identified with its excessive brittleness. It was reported that the increase in the compressive strength of the concrete results in an increase in the brittleness of the concrete.

Helices are normally used to confine the core of the concrete columns. However, for high strength concrete, the transverse reinforcement confinement is less efficient than in normal strength concrete when used in columns [3-5]. Furthermore, the ACI 318-14 [6] set the limits for the degree of confinement by setting the pitch of the helices as minimum as $25 \mathrm{~mm}$ in order to avoid the congestion of the helices in the columns. As such, helices are less efficient when used in the RPC columns. The need to improve the properties of the RPC material is crucial to mitigate the brittleness issue.

The incorporation of steel fibre in the concrete enhances the tensile strength, flexural strength and the toughness of the concrete [7-10]. The way the steel fibre works is by bridging the developed cracks due to the applied compressive loads or shrinkage and prevents the widening of cracks. This action continues until the steel fibres debond from the concrete. As a result, the concrete that includes steel fibre exhibits higher strength and toughness compared to non-fibrous concrete [11-13]. Moreover, the geometry of steel fibres plays a key role in improving the properties of the concrete. For example, Olivito and Zuccarello [14] and Xia et al. [15] stated that length of the steel fibre greatly affect the post ultimate behaviour, 
toughness and the load carrying capacity of the normal strength concrete. Abbas et al. [13] stated that short steel fibres affects the flexural properties more than the long steel fibres. Nataraja et al. [16] and Wu et al. [17] reported that the configuration of the steel fibres affects the ultimate load and the flexural load-deflection behaviour of normal strength concrete and the effect of the deformed steel fibres is more than the effect of smooth steel fibres.

In order to obtain full benefit from the incorporation of steel fibres in the concrete, several researchers attempted to incorporate two types of steel fibres in the concrete in a process called hybridization. The hybrid steel fibres is obtained by mixing two types of steel fibres of different properties in order to make use of the advantages of each steel fibre in improving the properties of the concrete. For instance, Kang et al. [18] investigated including straight steel fibres (0.2 $\mathrm{mm}$ diameter and 16.3-19.5 $\mathrm{mm}$ length) hybridized with different types of synthetic fibres (basalt, polyvinyl-alcohol, and polyethylene) in Ultra-High Strength Concrete (UHSC). Results of testing showed that the inclusion of steel fibres and synthetic fibres effectively improves the tensile strength of UHSC due to the effect of fibres on the crack development in different stages. Park et al. [19] investigated the effect of including different types of steel fibres of different geometrical shapes on the tensile behaviour of UHSC. It was concluded that the tensile stress-strain behaviour, post-crack behaviour and the strength was noticeably enhanced by the addition of the hybrid steel fibres that included micro smooth and macro twisted steel fibres. Furthermore, Glavind and Aarre [20], Larsen and Krenchel [21] and Feldman and Zheng [22] have investigated the effect of hybridization between steel fibres and polypropylene on the behaviour of concrete. The reported results showed the hybridization of steel fibres and polypropylene fibres results in the enhancement of the tensile strength and the fracture energy. The enhancement was attributed to the action of the steel fibres in improving the ultimate strength while the polypropylene fibres improved the energy absorption of concrete. Banthia and Sheng [23] reported that the incorporation of two types of 
fibres of different materials and moduli of elasticity such as steel fibres and carbon fibres enhanced the strength and the toughness of the concrete. The steel fibres improve the strength while the carbon fibres improve the toughness of the concrete. Al-Tikrite and Hadi [24] investigated the inclusion of steel fibre on the mechanical properties of RPC in individual and hybrid forms. Al-Tikrite and Hadi [24] concluded that the hybridization of steel fibres affects the ultimate stress, the corresponding strain and the modulus of elasticity effectively. Also, the post ultimate behaviour of RPC and the energy absorption of RPC were improved noticeably.

On the other hand, the negative aspect of utilizing the industrial steel fibres to reinforce the concrete is the high cost of steel fibres compared to the materials used to produce the concrete. It is estimated that the cost of $1 \%$ by volume of steel fibres included in the UltraHigh Strength Concrete (UHSC) is higher than the cost of the material used in the mixture [25]. Also, if the consumption of the natural resources is taken into consideration, the estimated amount of the industrial fibres that are produced annually is about 60 million tonnes around the world [26]. Moreover, the cost of steel fibres in some countries may not justify using it in the concrete [27]. Consequently, to save the cost of steel fibre and to conserve the natural resources, the need for searching for alternatives to the industrial steel fibres or to reduce the amount of steel fibres to be added without affecting the properties of the concrete has become important.

As such, this study, as a complementary work of a study conducted by Hadi and Al-Tikrite [28], investigated experimentally the effect of the inclusion of steel fibre on the behaviour of RPC columns under different loading conditions. The emphasis of the current work is the investigation of the influence of the inclusion of different types of steel fibres of different geometry in individual form and in hybrid form on the behaviour of RPC specimens under 
different loading conditions. The geometry of steel fibres, type (industrial and waste) and volume content is the main parameters that were considered in this study. Also, the feasibility of the inclusion of the waste steel fibres (WF) recovered from discarded tyres either individually or hybridised with the industrial steel fibres in the RPC column specimens tested under different loading conditions was investigated. Three different types of steel fibres of different geometry and volume contents were used: straight micro steel fibre (MF), macro deformed steel fibre (DF) and waste steel fibre (WF) recovered from discarded tyres. A hybridization of steel fibres was made up to produce waste-industrial hybrid steel fibre (WHF). The RPC column specimens that included MF and DF had been investigated by Hadi and Al-Tikrite [28]. For comparison purposes, the abovementioned two groups of column specimens were included in this research paper. A total of twenty RPC specimens of five groups were cast and tested in this study. Each group included four specimens, one tested under concentric loading, two were tested under eccentric loading (25 mm and $50 \mathrm{~mm}$ ) and one tested under flexural loading (four-point bending).

\section{Experimental Program}

\subsection{Materials}

Three different types of steel fibres of different geometries and volume contents were used: micro straight steel fibre (MF), macro deformed steel fibre (DF) and waste steel fibre (WF) recovered from discarded tyres. The ratio of MF, DF and WF used in this study were 4\%, $2 \%$ and $3 \%$, respectively. These ratios were shown to be the optimum ratios that improve the behaviour of RPC under loading based on an earlier study conducted by Al-Tikrite and Hadi [24] on RPC. A hybridization of steel fibre was made up by blending $50 \%$ of the best ratio of $\mathrm{WF}$ and $25 \%$ of the best ratios of MF and DF (1\% MF, $0.5 \% \mathrm{DF}$ and $1.5 \% \mathrm{WF})$ to produce the waste-industrial steel fibre (WHF) at 3\%. The hybridization of WF, MF and DF was done after the waste steel fibre WF was measured and grouped into ranges of average diameters 
and ranges of lengths. Afterwards, randomly selected $1.5 \%$ of WF was hybridized with $1 \%$ MF, $0.5 \%$ DF to form WHF.

The micro straight steel fibres used was of a diameter $(D=0.2 \mathrm{~mm})$, length $(L=6 \mathrm{~mm})$ and nominal tensile strength of $2900 \mathrm{MPa}$ [29]. The macro deformed steel fibre was of $(D=0.55$ $\mathrm{mm}, L=18 \mathrm{~mm}$ and nominal tensile strength $=800 \mathrm{MPa}$ ) [30]. The waste steel fibre recovered from discarded tyres was obtained from a local source.

The WF measurements were performed as follows [24]: waste steel fibres were randomly selected and distributed in ten groups of one hundred steel fibres. Measuring the length and the diameter of each steel fibre was done by a micrometre. The measurements were conducted on each steel fibre as follows: Three measurements for the diameter (one at each end and one in the middle) and one for the length. Also, a tensile strength test was conducted for two samples from each group. The WF was grouped into average diameters and range of lengths. The range of lengths and the percentage of WF were distributed according to the average diameters. The range of the average diameters and lengths measured with the percentage of each range is shown in Fig. 1 . The average length was $\left(L_{\text {average }}=22.2 \mathrm{~mm}\right)$, the average diameter was $\left(D_{\text {average }}=0.22 \mathrm{~mm}\right)$ and the average tensile strength was $1900 \mathrm{MPa}$. Fig. 2 shows steel fibres utilized in this study.

The RPC mixture reported by Al-Tikrite and Hadi [24] was utilized in this study. The targeted compressive strength of RPC is $100 \mathrm{MPa}$. Table 1 presents the constituents of the RPC mixture.

\subsection{Preparation of specimens, mixing and casting procedure}

To investigate the effect of different types of steel fibre included in the RPC circular column, five groups of twenty RPC specimens of $200 \mathrm{~mm}$ diameter and $800 \mathrm{~mm}$ length were cast and 
tested. The first group was the reference specimens which were non-fibrous RPC specimens (NF). The second group was the RPC specimens that included $4 \%$ micro straight steel fibres (MF). The third group was the RPC specimens that included $2 \%$ macro deformed steel fibres (DF). The fourth group was the RPC specimens that included 3\% waste steel fibre recovered from discarded tyres (WF). The fifth group was the RPC specimens that included 3\% industrial-waste hybrid steel fibres (WHF). Each group included four specimens, one tested under concentric loading, two tested under eccentric loading (25 mm and $50 \mathrm{~mm})$ and one tested under flexural loading.

To identify the RPC specimens, the specimens were labelled as follows: the first part of the label, NF, MF, DF, WF and WHF represents non-fibrous, micro steel fibre, deformed steel fibre, waste steel fibre and waste-industrial steel fibre, respectively. The second part of the label represents the loading conditions, E0, E25, E50 and PB, which represents concentric loading, $25 \mathrm{~mm}$ eccentric loading, $50 \mathrm{~mm}$ loading and flexural loading, respectively. For example, Specimen NF-E0 represents the RPC specimen which is non-fibrous specimen (reference) tested under concentric loading. Specimen MF-E25 represents the RPC specimen that included MF tested under eccentric loading at $25 \mathrm{~mm}$. Specimen DF-E50 represents the RPC specimen that included DF tested under eccentric loading at $50 \mathrm{~mm}$. Specimen WF-PB represents the RPC specimen that included WF tested under flexural loading (four-point bending).

All specimens were longitudinally reinforced with six N12 steel bars (12 mm diameter, deformed) and confined with steel helix R10 (10 mm diameter, smooth) of a diameter of 150 mm centre to centre. The yield strength of N12 and R10 are $515 \mathrm{MPa}$ and $320 \mathrm{MPa}$, respectively. The pitch of the helices was $40 \mathrm{~mm}$. The concrete cover was $20 \mathrm{~mm}$ from all sides. The reinforcement details for all specimens in this study were kept the same to 
demonstrate the effect of the steel fibre on the behaviour of RPC under different loading conditions. Table 2 shows the reinforcement details of the specimens.

The moulds utilized to cast the specimens in this study were plastic tube moulds of $200 \mathrm{~mm}$ inner diameter and $800 \mathrm{~mm}$ length. The plastic tube moulds were affixed vertically by a wooden formwork that was built in the laboratory. The longitudinal steel bars N12 were cut to length of $760 \mathrm{~mm}$. The helix R10 was coiled at a diameter of $150 \mathrm{~mm}$ centre to centre. An aluminium spacer was used to keep the spacing between the helices at $40 \mathrm{~mm}$. The helix was fixed vertically to a steel plate base. Two horizontal spacers were used, one at the bottom and one at the top to position the longitudinal bars accurately. Next, the longitudinal steel bars were tied to the helix to form the steel reinforcement frame. Then, the steel reinforcement frames were placed in the plastic tube moulds and prepared for casting. Figures 3 and 4 show the fabrication and steel reinforcement details of the tested specimens, respectively.

Mixing and casting procedure of RPC was performed according to Al-Tikrite and Hadi [24]. Firstly, the dry materials including the cement, silica fume, silica flour and the natural fine sand were placed in the pan of the mixer and mixed for about 4 minutes. Next, $80 \%$ and $50 \%$ of the water and superplasticiser, respectively, were mixed together separately and added to the dry mix and mixed for about 5 minutes. Afterwards, the remaining $20 \%$ of the water and $50 \%$ of the superplasticiser were mixed separately and added to the mixture and mixing process continued for an extra 5 minutes until the particles of the constituents started to form flocks of concrete which is called breaking point. Next, the steel fibres were added to the mixture and the mixing process continued for further 4 minutes after the addition of steel fibres until the mixture turned to a flowable mixture. Then, the flowable RPC was placed in the plastic moulds in layers in order to avoid the entrapment of air voids. 
The curing was done by covering the RPC specimens by a wet hessian fabric to provide a moist environment for the specimens. Also, plastic sheets were used to cover the hessian fabric to prevent the evaporation of the curing water. The curing continued for 27 days then the specimens were prepared for testing.

\subsection{Instrumentation and testing procedure}

Two Linear Variable Differential Transducers (LVDTs) were externally instrumented in addition to the LVDT of the testing machine to record the total axial deformation. The lateral deformation that results from eccentric loading and bending loading was recorded by a laser triangulation installed on the testing machine at mid-height and mid-span of the specimen tested under eccentric loading and bending loading, respectively.

A compression testing machine of a capacity of $5000 \mathrm{kN}$ was used for testing the specimens under different loading conditions. The ends of the specimens that were tested as columns were capped with a high strength plaster to ensure levelling of the specimens and provide uniform surfaces. Also, the specimens were wrapped with a single layer of $100 \mathrm{~mm}$ wide CFRP at the ends to prevent the premature failure. Two circular loading heads were used at the top and bottom of the specimens to apply loading (concentric or eccentric). The loading heads include three grooves located at the centre, $25 \mathrm{~mm}$ and $50 \mathrm{~mm}$. Two surface loading adjustment plates were used to fit to the groove depending on the type of loading (See Figure 5). The surface loading adjustment plates touch the loading plates of the testing machine and transfer the load through the loading knives to the specimen. Figure 5 shows the axial loading equipment of the tested specimens.

The loading system shown in Figure 6 was used to test the specimens under flexural loading. The loading system consists of two parts. The upper part consists of two rings placed at the 
top of the specimen and the lower part consists of two rings placed at the bottom of the specimen to allow the specimen to bend under flexural loading without experiencing crushing at the loading points and at supports. The length of the beam span was $700 \mathrm{~mm}$ divided into three equal lengths of $233.3 \mathrm{~mm}$. To prevent the shear failure that might occur due to the short span length to depth ratio of the reference specimen and to guarantee the deflection at midspan, the plain RPC specimens (reference) were wrapped with two layers of CFRP at the shear span from both sides. Also, to have a consistent comparison with the reference, the RPC specimens that included steel fibres were also wrapped with CFRP at the shear span.

The specimens were tested by loading them with a displacement controlled load at a rate of $0.005 \mathrm{~mm} / \mathrm{s}$ until failure. A data logger was connected to the LVDTs and the laser triangulation to record the data every 2 seconds.

\section{Experimental test results and analysis}

\subsection{Modes of Failure}

The mode of failure of the tested specimens was governed by loading condition and presence of fibres. All specimens were tested until failure. It was observed that hairline cracks appeared in the midheight of the tested specimen at reaching the ultimate axial load that the specimens can withstand. Afterwards, the load carrying capacity of the specimen started to decrease until the fracture of the helix.

It was noticed that the non-fibrous RPC specimens (reference) tested under concentric loading, eccentric loading $(25 \mathrm{~mm}$ and $50 \mathrm{~mm}$ ) and flexural loading failed in a brittle manner with a loud smashing sound of the concrete cover after reaching the ultimate load followed by a sudden drop of the load sustained by the specimens. However, the RPC specimens that included steel fibres and tested under the same loading conditions did not exhibit brittle 
failure and the failure after reaching the ultimate axial load was gradual with a sound of ticking resulted from the debonding of fibres from the concrete. Also, the concrete cover did not exhibit full detachment from the concrete core due to the presence of steel fibres that bridge the cracks and connect the concrete cover with the concrete core.

For specimens tested under eccentric and flexural loading, the failure started by crushing of concrete at the compression zone at midheight of specimens. Vertical hairline cracks appeared at the compression face while transverse cracks appeared at the tension face. With the increase in the applied loads, the mouth of the cracks at the tension face started to widen while the concrete in the compression face started to crush. It was observed that the concrete cover of the reference specimens tested under eccentric loading exhibited full detachment nearly along the whole length of the specimen at the compression face. However, the presence of steel fibres in the RPC specimens delayed the crushing of concrete at the compression face through the bridging action of the steel fibres that inhibit the initiation and propagation of cracks. Consequently, the failure of RPC that included steel fibres after reaching the ultimate axial load was gradual until bonding failure of steel fibres with the matrix. Afterwards, the concrete core which was dilated due to the initiated cracks started to apply stresses on the confining helices which provide the concrete core with adequate stiffness to sustain the applied load [31]. The concrete core sustained the applied loads until failure. The failure occurred by the fracture of the helices.

In summary, the presence of steel fibres resulted in the load carrying capacity after reaching the ultimate axial load was decreased gradually until debonding of steel fibres of the concrete whereas the concrete core which was dilated due to the initiated cracks started to apply stresses on the confining helices to sustain the applied load. Figures 7 and 8 shows the failure modes of the tested specimens. 


\subsection{RPC specimens tested under concentric axial load}

290

291

Five RPC specimens with and without steel fibres were tested under concentric axial load. Table 3 presents the results of the specimens loaded concentrically. It was observed that the addition of steel fibres affected the ultimate axial load of the RPC specimens positively. In particular, the inclusion of MF in the RPC specimen has attained the highest increase in the ultimate axial load under concentric loading in comparison with the other types of steel fibres. The load carrying capacity of Specimen MF-E0 was 32\% higher than the ultimate axial load of Specimen NF-E0. This is because short or micro steel fibre affects the strength of concrete more than long steel fibres due to controlling of the early cracking of concrete [32] and the uniform distribution of the micro steel fibres throughout the matrix without entangling between each other. The load carrying capacity of Specimens DF-E0, WF-E0 and WHF-E0 was increased by $9 \%, 23 \%$ and $23 \%$, respectively, compared to the load carrying capacity Specimen NF-E0.

The addition of steel fibre had positively affected the post ultimate behaviour of the RPC specimens through softening of the descending branch of the load-deformation curve and preventing the sudden failure. The improvement of the descending branch of the loaddeformation curve comes from an additional action provided by steel fibres through the bond between the steel fibres and the concrete [33]. The action of fibres was noticeable from the ultimate axial load until debonding of fibres from the concrete in the concrete cover whereas the transverse steel reinforcement confinement proceeds to fully sustain the applied load. The effect of steel fibres on the post ultimate behaviour of RPC specimens was noticeable in terms of energy absorption. The energy absorption is defined as the ratio of the area under the load- 
deformation curve up to the postultimate load to the area under the load-deformation curve up to the yield load [34-37]:

$$
\lambda=\frac{A_{\delta_{u}}}{A_{\delta y}}
$$

where, $\lambda$ is the energy absorption of RPC specimen, $A_{\delta_{y}}$ is the area under load-deformation curve calculated from zero to the deformation that corresponds to the yield axial load and $A_{\delta_{u}}$ is the area under the load-deformation curve calculated from zero to the postultimate axial deformation that corresponds to $85 \%$ of the ultimate axial load $[34,38]$. The yield axial load was found by drawing two lines. The first line is a tangent to the load-deformation curve and meets the curve at the origin. The second line is a horizontal line that touches the curve at the ultimate axial load. Next, a vertical line is drawn from the intersection of these two lines. The point that the vertical line intersects the curve represents the yield point [28, 39]. Figure 9 illustrates the calculation of the energy absorption of the tested specimens.

The post ultimate behaviour of the RPC specimens, however, was different depending on the type, geometry and amount of steel fibres included in the RPC specimen. Specimen NF-E0, after reaching the ultimate axial load of $3304 \mathrm{kN}$, experienced a sudden failure in a brittle manner with smashing sound due to the spalling of the concrete cover. The load carrying capacity dropped by $22 \%$ to $2564 \mathrm{kN}$ at an axial deformation of $4.6 \mathrm{~mm}$. Afterwards, the applied load was sustained by the confined core that withstood the applied load until the fracture of the helix at an axial deformation of $21.5 \mathrm{~mm}$ that corresponds to an axial load of $1633 \mathrm{kN}$.

For Specimens MF-E0 and DF-E0, the addition of MF and DF delayed the early spalling of the concrete cover after reaching the ultimate load carrying capacities of $4373 \mathrm{kN}$ and 3607 $\mathrm{kN}$, respectively, and prevented the sudden failure of the load. Also, the descending branch of 
the axial load-axial deformation curve was gradual until axial loads of $3483 \mathrm{kN}$ and $2668 \mathrm{kN}$, respectively, at axial deformations of $6.5 \mathrm{~mm}$ and $6.3 \mathrm{~mm}$, respectively. Afterwards, the confined core sustained the load until failure. Specimens MF-E0 and DF-E0 failed at axial loads of $1900 \mathrm{kN}$ and $1791 \mathrm{kN}$, respectively, at axial deformations of $21.7 \mathrm{~mm}$ and $22.4 \mathrm{~mm}$, respectively. The energy absorption of Specimens MF-E0 and DF-E0 was increased by $16 \%$ and $2 \%$, respectively, compared to Specimen NF-E0. The increase in the energy absorption of Specimen DF-E0 was the lowest compared with its counterparts. This might be attributed to the sudden widening of the initiated cracks that caused the slippage of DF that bridges the macro cracks and resists widening of cracks until the applied load that caused widening of cracks become larger than the bonding between DF and the matrix leading to slippage of fibres [40].

The incorporation of WF in the RPC specimens has a positive impact on the ultimate axial load and post ultimate behaviour of the RPC specimens. The load carrying capacity of Specimen WF-E0 was increased by $15 \%$ compared to Specimen NF-E0. The WF has effectively delayed the early spalling of the concrete cover after reaching the ultimate load carrying capacity. The load carrying capacity of Specimen WF-E0 after reaching the ultimate axial load was decreased gradually up to an axial load of $2685 \mathrm{kN}$ at an axial deformation of $7.3 \mathrm{~mm}$. Specimen WF-E0 failed at an axial load of $1495 \mathrm{kN}$ at an axial deformation of 38.1 $\mathrm{mm}$. The energy absorption of Specimen WF-E0 was increased by 58\% compared to the energy absorption of Specimen NF-E0.

The addition of the hybrid steel fibres (WHF) improved the post ultimate behaviour of the RPC specimens noticeably. The early spalling of the concrete cover was effectively delayed by WHF up to the ultimate load carrying capacity of $4066 \mathrm{kN}$. Afterwards, the load carrying capacity decreased gradually up to an axial load of $2577 \mathrm{kN}$ at an axial deformation of 7.4 
$\mathrm{mm}$. The energy absorption of Specimen WHF-E0 was improved by $67 \%$ compared with the energy absorption of Specimen NF-E0. The improvement in the post ultimate behaviour of Specimen WHF-E0 could be attributed to the combined action of steel fibres, the short or the micro steel fibres bridge the micro cracks while the long steel fibres bridge the macro cracks and prevents widening of cracks [41]. Specimen WHF-E0 failed at an axial load of $1459 \mathrm{kN}$ at an axial deformation of $45.5 \mathrm{~mm}$. Fig. 10 (a) shows the behaviour of the tested RPC specimens under concentric loading.

The configuration of steel fibres plays a key role in enhancing the behaviour of the RPC specimens. For instance, the RPC specimens that included DF which bridges the macro cracks have presented early debonding from the concrete due to the slippage of the steel fibre from the matrix when the applied load become higher than the bond between DF and the matrix. However, The RPC specimens that included MF which is straight steel fibres that bridges micro cracks have presented delayed debonding from the matrix. Also, the RPC that included WF of variant geometrical shapes, as a result of the recovery process from discarded tyres, have shown delayed debonding from the RPC matrix compared to DF. This might be attributed to the entrapped air in the corrugation of the deformed steel fibres which causes lack of contact along the steel fibre with the matrix and finally less bonding between the steel fibre and the matrix.

It was noticed that the provided confinement for the column is not significant especially for the non-fibrous RPC specimens. This is due to the excessive brittleness of RPC that is known of lack of ductility and experiences sudden failure when the maximum strength is reached. Moreover, the dilation of RPC is very low due its brittleness. As such, the provided confinement from the confining helices for RPC specimens is very low due to the failure of concrete material before the dilated concrete core applies stresses on the confining helices to 
provide the concrete core with adequate stiffness to sustain the applied load. For instance, for the non-fibrous RPC specimens, a total spalling of the concrete cover occurred at reaching the ultimate axial load followed by a sudden drop in the load carrying capacity was noticed. However, the inclusion of steel fibres as a solution for mitigating the brittleness issue in the RPC specimens resulted in the load carrying capacity after reaching the ultimate axial load to decrease gradually until debonding of steel fibres from the concrete whereas the concrete core withstood the applied load up to failure.

\subsection{RPC specimens tested under eccentric axial load}

Ten RPC specimens were tested under eccentric loading. Five specimens were subjected to eccentric loading at $25 \mathrm{~mm}$ eccentricity and five specimens were subjected to eccentric loading at $50 \mathrm{~mm}$ eccentricity. Table 4 presents the results of the tested specimens under eccentric loading. It was observed that all of the specimens that were subjected to eccentric loading have experienced crushing of the concrete cover at the compression face at reaching the ultimate load carrying capacity. The concrete cover of Specimens NF-E25 and NF-E50 has almost spalled off at the compression face. The ultimate load carrying capacity of Specimens NF-E25 and NF-E50 were $2194 \mathrm{kN}$ and $1327 \mathrm{kN}$, respectively. After reaching ultimate axial load, the load carrying capacity of Specimens NF-E25 and NF-E50 dropped suddenly by $29 \%$ and $51 \%$, respectively, to $1705 \mathrm{kN}$ and $878 \mathrm{kN}$, respectively. Then, the applied load was sustained by the confined concrete core of Specimens NF-E25 and NF-E50 until the fracture of confining helix at axial loads of $549 \mathrm{kN}$ and $349 \mathrm{kN}$, respectively.

The inclusion of steel fibres in the RPC specimens delayed the early spalling of the concrete cover which resulted in an increase in the load carrying capacity of the RPC specimens. The load carrying capacity of Specimen MF-E25 was $2835 \mathrm{kN}$ which is about $29 \%$ higher than the load carrying capacity of Specimen NF-E25. The energy absorption of Specimen MF-E25 
was improved by $21 \%$ compared to the energy absorption of Specimen NF-E25. The load carrying capacity of Specimen MF-E50 was $1711 \mathrm{kN}$ which is about 29\% higher than the load carrying capacity of Specimen NF-E50. The energy absorption of Specimen MF-E50 was improved by $41 \%$ compared to the energy absorption of Specimen NF-E50. The descending branch of the load-deformation curve of Specimens MF-E25 and MF-E50 was softened after reaching the ultimate load carrying capacity up to axial loads of $2025 \mathrm{kN}$ and $1405 \mathrm{kN}$, respectively. Then, the transverse steel confinement started to sustain the applied loads until the failure of specimens.

The load carrying capacity of Specimen DF-E25 increased by $2 \%$ compared to Specimen NFE25. After reaching the ultimate load carrying capacity, the load carried by Specimen DF-E25 decreased about $31 \%$ to an axial load of $1710 \mathrm{kN}$. The energy absorption of Specimen DFE25 was higher than the energy absorption of Specimen NF-E25 by $2 \%$. The load carrying capacity of Specimen DF-E50 increased by $7 \%$ compared to the load carrying capacity of Specimen NF-E50. After reaching the ultimate axial load, the load carrying capacity of the specimen decreased by about $44 \%$ to an axial load of $980 \mathrm{kN}$. The energy absorption of Specimen DF-E50 was higher than the energy absorption of Specimen NF-E50 by $4 \%$. The lower energy absorption provided by DF could be attributed to the slippage of DF that arrests the macro cracks; cracks that were initiated in the concrete due to loading; when a sudden widening of cracks occurred which caused the bonding between DF and the matrix to become lower than the applied load that caused widening of crack and resulted in slippage of DF [42].

The inclusion of WF in the RPC specimen has positively affected the load carrying capacity and the energy absorption under eccentric loading. The load carrying capacity of Specimen WF-E25 was $2496 \mathrm{kN}$ which is $14 \%$ higher than the load carrying capacity Specimen NFE25. The load carrying capacity of Specimen WF-E50 was $1576 \mathrm{kN}$ which is $19 \%$ higher 
441 than the load carrying capacity of Specimen NF-E50. The WF that was included in

442 Specimens WF-E25 and WF-E50 has kept the concrete cover attached to the concrete core 443 after reaching the ultimate axial load and effectively softened the descending branch up to 444 axial loads of $2056 \mathrm{kN}$ and $1422 \mathrm{kN}$, respectively. The energy absorption of Specimen WFE25 was higher than the energy absorption of Specimens NF-E25 by 36\%. Also, the energy absorption of Specimen WF-E50 was 45\% higher than the energy absorption of Specimen NF-E50. This is due to the WF includes different sizes of steel fibres as a result of the recovery process which combines between the actions of the short and long steel fibres in RPC in inhibiting the cracks' initiation and propagation. Also, the diversity of the geometry of WF provides a very good bonding with the matrix and results in a considerable restraining of widening of cracks through bridging the macro cracks and finally prevents the spalling of the concrete cover to latter stages.

The load carrying capacity of Specimen WHF-E25 increased by $15 \%$ compared to the load carrying capacity of Specimen NF-E25. Also, the load carrying capacity of Specimen WHFE50 increased by $14 \%$ compared to the load carrying capacity of Specimen NF-E50. The post ultimate behaviour of Specimens WHF-E25 and WHF-E50 was improved under eccentric loading up to axial loads of $2141 \mathrm{kN}$ and $1304 \mathrm{kN}$, respectively. The energy absorption of Specimen WHF-E25 was improved by $38 \%$ in comparison with the energy absorption of Specimens NF-E25. Also, the energy absorption of Specimen WHF-E50 improved by $45 \%$ compared to the energy absorption of Specimen NF-E50. This might be due to the combined action of the short and long steel fibres in inhibiting the initiation and the widening of cracks and finally keep the concrete cover attached to the concrete core to latter stages. Figure 10 (b) and (c) shows the behaviour of the tested RPC specimens under $25 \mathrm{~mm}$ and $50 \mathrm{~mm}$ eccentric loading. 


\subsection{RPC specimens tested under flexural loading (four-point bending)}

Five Specimens (NF-PB, MF-PB, DF-PB, WF-PB and WHF-PB) were tested under flexural loading to investigate the behaviour of specimens under pure flexural load. Table 5 presents the experimental results of the tested specimens under flexural loading. Figure 10 (d) shows the flexural load-midspan deflection curves of the tested specimens.

The ascending branch of the curve was linear for all specimens. The ultimate flexural load sustained by Specimen NF-PB (the reference) was $356 \mathrm{kN}$ while Specimens MF-PB, DF-PB, WF-PB and WHF-PB had sustained about 10\%, 6\%, 13 and 9\% higher flexural load, respectively, than the reference specimen sustained. Afterwards, the load sustained by the Specimen NF-PB after reaching the ultimate flexural load dropped suddenly by about $23 \%$ to a flexural load of $274 \mathrm{kN}$. This drop was because of the crushing of concrete cover at the compression face of the specimen. However, the addition of steel fibres to the RPC specimens has softened the descending branch of the load-deflection curve noticeably. The load sustained by Specimens MF-PB and DF-PB after reaching the ultimate flexural load decreased gradually to $371 \mathrm{kN}$ and $329 \mathrm{kN}$, respectively, at a corresponding midspan deflection of $11.7 \mathrm{~mm}$ and $8.03 \mathrm{~mm}$, respectively.

The ultimate flexural load of Specimen WF-PB was $403 \mathrm{kN}$ which is $13 \%$ higher than the ultimate flexural load of the corresponding reference specimen. The load sustained by Specimen WF-PB after reaching the ultimate load decreased gradually to a flexural load of $370 \mathrm{kN}$ at a corresponding midspan deflection of $11.4 \mathrm{~mm}$. The energy absorption of Specimen WF-PB was 470\% higher than the energy absorption of Specimen NF-PB. Also the energy absorption of Specimen WF-PB was higher than the energy absorption of Specimens MF-PB, DF-PB and WHF-PB. This is attributed to good bonding between WF and RPC which requires a higher load to pull the fibres out of the concrete. Also, the homogenous distribution of WF throughout the section inhibits the initiation of the micro cracks and the 
widening of the macro cracks as the WF includes different sizes of steel fibre of different lengths which enables WF to have combined actions of the short, middle and long steel fibres and delayed the spalling of the concrete cover to latter stages. Similar finding were reported by Aiello et al. [43] in regards to flexural strength of concrete reinforced with WF.

The addition of WHF to RPC increased the ultimate flexural load of Specimen WHF-PB by 9\% compared to Specimen NF-PB and achieved a ultimate flexural load of $389 \mathrm{kN}$. The descending branch of the load-deflection curve was softened effectively and the decrease in the load sustained by the specimen after reaching the ultimate load was gradual up to a load of $356 \mathrm{kN}$ at a corresponding midspan deflection of $13.5 \mathrm{~mm}$.

\section{Experimental axial load-bending moment interaction diagram ( $P$ - $M$ diagram)}

For design purposes of columns subjected to different loading conditions, an experimental axial load-bending moment interaction diagram ( $P-M$ diagram) was drawn based on the test results. The ultimate axial loads and the ultimate bending moments of the RPC specimens tested under concentric loading, eccentric loading $(25 \mathrm{~mm}$ and $50 \mathrm{~mm})$ and flexural loading were used to construct the $P-M$ diagram. The $P-M$ diagram was constructed from four points. The first point represents the ultimate axial load obtained from the specimens tested under concentric loading. The second and third points represent the ultimate eccentric axial loads obtained from the specimens tested under eccentric loading at $25 \mathrm{~mm}$ and $50 \mathrm{~mm}$. The fourth point represents the ultimate bending moment that corresponds to the ultimate flexural load obtained from specimens tested under flexural loading.

For the second and third points in the $P-M$ diagram, the ultimate moment that corresponds to the ultimate axial load of RPC specimens tested under eccentric load (25 mm and $50 \mathrm{~mm}$ ) was calculated as follows: 


$$
M_{u}=P_{u}\left(e+\delta_{\text {midhight }}\right)
$$

where, $M_{u}$ is the ultimate moment corresponding to the ultimate axial load, $P_{u}$ is the ultimate axial load, $e$ is the load eccentricity and $\delta_{\text {midhight }}$ is the ultimate lateral deformation that corresponds to the ultimate axial deformation at midheight.

The fourth point is the ultimate bending moment that corresponds to the ultimate flexural load obtained from the specimens tested under flexural loading. The ultimate moment was calculated as follows:

$$
M_{f, u}=P_{f, u} \times L / 6
$$

where, $M_{f, \max }$ is the ultimate moment that corresponds to the ultimate flexural load, $P_{f, p}$ is the ultimate flexural load, $L$ is span length of the flexural test. Table 6 presents the experimental ultimate axial loads and the corresponding ultimate moments of the tested specimens under concentric, eccentric and flexural loading.

The inclusion of steel fibres in the RPC specimens has increased the ultimate axial load and the corresponding moment considerably in comparison with the reference specimens (NF). However, these increases were dependant on the steel fibres content, geometry and type. The MF specimens showed the highest axial load and bending moment due to the effect of the MF on the strength of the RPC through the inhibition of the initiation and propagation of the micro cracks. The DF specimens showed the lowest ultimate axial load and lowest ultimate moment compared with the RPC specimens that included MF, HF, WF and WHF. This is because of the slippage of DF from the matrix due to the sudden widening of the macro cracks the DF bridges. The WF and WHF specimens showed axial loads and bending moments lower than the axial load and bending moment of MF specimens. The reason for this is WF and WHF affect the post ultimate behaviour more than the ultimate axial load. It is 
worth to mention that the results of the tested specimens that included different types of steel

543 fibres were consistent and the comparisons among the experimental results obtained indicate the possibility of repeatability of the results. Figure 11 shows the experimental $P-M$ interaction diagram of the tested specimens under concentric, eccentric $(25 \mathrm{~mm}, 50 \mathrm{~mm})$ and flexural loading.

\section{Conclusion}

The experimental results of testing twenty RPC specimens that incorporated MF, DF, WF and WHF under concentric, eccentric and flexural loading (four-point bending) are presented in this paper. The following conclusion can be withdrawn:

1. The mode of failure of the tested specimens was governed by loading condition and presence of fibres. The non-fibrous RPC specimens experienced an early spalling of the concrete cover at reaching the ultimate axial load then a sudden drop of the load carrying capacity was observed. However, the inclusion of the steel fibres effectively delayed the early spalling of the concrete cover beyond the ultimate axial load until the pull out of the fibres from the concrete with gradual decrease of the load carrying capacity. Also, the concrete cover did not exhibit full detachment from the concrete core after failure.

2. The addition of MF increased the load carrying capacity of the RPC specimens considerably compared to the other steel fibres utilized while the inclusion of DF in the RPC marginally affected the load carrying capacity compared to its counterpart.

3. The quantity of WF and WHF included in the RPC column specimens is lower than the quantity of MF which saves the cost of fibres needed to enhance the behaviour of the RPC column specimen under loading. Moreover, the WF column specimens showed better behaviour than WHF and DF column specimens and competitive improvement compared to MF column specimens under different loading conditions which favours economic and environmental aspects. 
4. The incorporation of WF in the RPC achieved a comparable increase in the ultimate axial load from $13 \%$ to $23 \%$ and the energy absorption from $36 \%$ to $470 \%$, compared to the corresponding reference specimens under different loading conditions. Also, the inclusion of WF hybridized with industrial steel fibre enhanced the ultimate axial load from $9 \%$ to $23 \%$ and the energy absorption by $38 \%$ to $453 \%$ compared to the corresponding reference specimens under different loading conditions.

5. The postultimate deformation corresponding to $85 \%$ of the ultimate axial load was markedly improved by the addition of steel fibres. In comparison with the corresponding reference specimens under different loading conditions, the postultimate deformation was improved from $37 \%$ to $297 \%$ when MF was incorporated and from $3 \%$ to $251 \%$ when DF was incorporated. The inclusion of WF in the RPC specimens increased the postultimate deformation from $37 \%$ to $523 \%$ and from $34 \%$ to $357 \%$ when WHF was included.

6. The inclusion of DF in the waste-industrial hybridization of steel fibres (WHF) affected the behaviour of the RPC column specimens and decreased the influence of hybridization on the concrete adversely. As such, the hybridization of WF and MF without DF might be more reliable and should be further investigated.

In summary, although using a smaller quantity of fibres, the hybridization of steel fibres effectively increased the load carrying capacity and the energy absorption of RPC specimens. However, the total content of the fibres is identical to the one with WF and the content of WF is lower. As a result, the economic and environmental impacts are lower than in WF case. Therefore, the inclusion of WF in the RPC specimens as a full replacement is more preferable economically and environmentally and is feasible and effective in improving the behaviour of RPC under different loading conditions. Finally, WF is considered as a promising material for enhancing the behaviour of RPC under different loading conditions. 


\section{Acknowledgement}

596 The authors would like to express their gratitude to the technical officers in the High Bay 597 Laboratories of the University of Wollongong, Australia and for their support in performing 598 the experimental work especially for Mr. Ritchie McLean. Also, the authors would like to 599 thank Fibercon Australia for providing deformed steel fibres. The first author would like to 600 acknowledge the Iraqi Government and University of Wollongong, Australia for providing 601 him with full support for his PhD scholarship.

602

\section{References}

604 [1] P. Richard, M.H. Cheyrezy, Reactive powder concretes with high ductility and 200-800 MPa 605 compressive strength, Special Publication 144 (1994) 507-518.

606 [2] P. Aitcin, Concrete the most widely used construction materials, ACl Special Publication 154 $607 \quad$ (1995) 257-266.

608 [3] D. Cusson, P. Paultre, High-strength concrete columns confined by rectangular ties, Journal of 609 Structural Engineering 120(3) (1994) 783-804.

610 [4] M. Mansur, M. Chin, T. Wee, Stress-strain relationship of high-strength fiber concrete in compression, Journal of materials in civil engineering 11(1) (1999) 21-29.

612 [5] P. Paultre, R. Eid, Y. Langlois, Y. Lévesque, Behavior of steel fiber-reinforced high-strength concrete columns under uniaxial compression, Journal of Structural Engineering 136(10) (2010)

614

615

616

617 618 619 $1225-1235$.

[6] A. Committee, A.C. Institute, I.O.f. Standardization, Building code requirements for structural concrete ( $\mathrm{ACl}$ 318-14) and commentary, American Concrete Institute, 2014.

[7] S.P. Shah, Do fibers increase the tensile strength of cement-based matrix?, Materials Journal 88(6) (1992) 595-602.

[8] P.N. Balaguru, S.P. Shah, Fiber-reinforced cement composites, 1992. 
[9] A. Bentur, S. Mindess, Fibre reinforced cementitious composites, CRC Press2006.

[10] Ş. Yazıcı, G. İnan, V. Tabak, Effect of aspect ratio and volume fraction of steel fiber on the mechanical properties of SFRC, Construction and Building Materials 21(6) (2007) 1250-1253.

[11] M.N. Soutsos, S.G. Millard, K. Karaiskos, Mix design, mechanical properties, and impact resistance of reactive powder concrete (RPC), International workshop on high performance fibrereinforced cementitious composites in structural applications, 2005, pp. 549-560.

[12] N.P. Lee, D.H. Chisholm, Reactive powder concrete, 2005.

[13] S. Abbas, A.M. Soliman, M.L. Nehdi, Exploring mechanical and durability properties of ultra-high performance concrete incorporating various steel fiber lengths and dosages, Construction and Building Materials 75 (2015) 429-441.

[14] R. Olivito, F. Zuccarello, An experimental study on the tensile strength of steel fiber reinforced concrete, Composites Part B: Engineering 41(3) (2010) 246-255.

[15] H. Xia, W. Wang, Z. Shi, Mechanical properties of reactive powder concrete with ultra-short brass-coated steel fibres, Magazine of Concrete Research 67(6) (2015) 308-316.

[16] M.C. Nataraja, N. Dhang, A.P. Gupta, Stress-strain curves for steel-fiber reinforced concrete under compression, Cement and Concrete Composites 21(5-6) (1999) 383-390.

[17] Z. Wu, C. Shi, W. He, L. Wu, Effects of steel fiber content and shape on mechanical properties of ultra high performance concrete, Construction and Building Materials 103 (2016) 8-14.

[18] S.-T. Kang, J.-I. Choi, K.-T. Koh, K.S. Lee, B.Y. Lee, Hybrid effects of steel fiber and microfiber on the tensile behavior of ultra-high performance concrete, Composite Structures 145 (2016) 37-42.

[19] S.H. Park, D.J. Kim, G.S. Ryu, K.T. Koh, Tensile behavior of ultra high performance hybrid fiber reinforced concrete, Cement and Concrete Composites 34(2) (2012) 172-184.

[20] M. Glavind, T. Aarre, High-strength concrete with increased fracture-toughness, MRS Proceedings, Cambridge Univ Press, 1990, p. 39.

[21] E.S. Larsen, H. Krenchel, Durability of FRC-materials, MRS Proceedings, Cambridge Univ Press, 1990, p. 119. 
[22] D. Feldman, Z. Zheng, Synthetic fibres for fibre concrete composites, MRS Proceedings,

647 Cambridge Univ Press, 1993, p. 123.

648 [23] N. Banthia, J. Sheng, Micro-reinforced cementitious materials, MRS Proceedings, Cambridge 649 Univ Press, 1990, p. 25.

650 [24] A. Al-Tikrite, M.N. Hadi, Mechanical properties of reactive powder concrete containing industrial 651 and waste steel fibres at different ratios under compression, Construction and Building Materials 154 $652 \quad$ (2017) 1024-1034.

653 [25] D.J. Kim, S.H. Park, G.S. Ryu, K.T. Koh, Comparative flexural behavior of hybrid ultra high 654 performance fiber reinforced concrete with different macro fibers, Construction and Building 655 Materials 25(11) (2011) 4144-4155.

656 [26] A. Bartl, A. Hackl, B. Mihalyi, M. Wistuba, I. Marini, Recycling of fibre materials, Process Safety and Environmental Protection 83(4) (2005) 351-358.

658 [27] C. Achilleos, D. Hadjimitsis, K. Neocleous, K. Pilakoutas, P.O. Neophytou, S. Kallis, Proportioning 659 of steel fibre reinforced concrete mixes for pavement construction and their impact on environment 660 and cost, Sustainability 3(7) (2011) 965-983.

661 [28] M.N. Hadi, A. Al-Tikrite, Behaviour of fibre-reinforced RPC columns under different loading 662 conditions, Construction and Building Materials 156 (2017) 293-306.

663 [29] G.D.M.F.C. Ltd., <http://www.gzdymf.com/index en.html>, 2017 (accessed 15 July. 2017).

664 [30] Fibercon, <http://www.fibercon.com.au/>, 2017 (accessed 15 July.2017).

665 [31] H. Karim, M.N. Sheikh, M.N. Hadi, Axial load-axial deformation behaviour of circular concrete 666 columns reinforced with GFRP bars and helices, Construction and Building Materials 112 (2016) $667 \quad 1147-1157$.

668 [32] P. Bhargava, U.K. Sharma, S.K. Kaushik, Compressive stress-strain behavior of small scale steel 669 fibre reinforced high strength concrete cylinders, Journal of advanced concrete technology 4(1) $670 \quad$ (2006) 109-121. 
[33] W.-C. Liao, W. Perceka, E.-J. Liu, Compressive Stress-Strain Relationship of High Strength Steel

672 Fiber Reinforced Concrete, Journal of Advanced Concrete Technology 13(8) (2015) 379-392.

673 [34] M.N. Hadi, T.M. Pham, X. Lei, New method of strengthening reinforced concrete square columns

674 by circularizing and wrapping with fiber-reinforced polymer or steel straps, Journal of Composites for 675 Construction 17(2) (2012) 229-238.

676 [35] M.N. Hadi, I.B.R. Widiarsa, Axial and flexural performance of square RC columns wrapped with 677 CFRP under eccentric loading, Journal of Composites for Construction 16(6) (2012) 640-649.

678 [36] M.N.S. Hadi, Reinforcing Concrete Columns with Steel Fibres, Asian Journal of Civil Engineering 679 (Building and Housing) 10(1) (2009) 79-95.

680

[37] A. Saljoughian, D. Mostofinejad, Corner Strip-Batten Technique for FRP-Confinement of Square 681 RC Columns under Eccentric Loading, Journal of Composites for Construction 20(3) (2015) 04015077. [38] S. Pessiki, A. Pieroni, Axial load behavior of large-scale spirally-reinforced high-strength concrete columns, ACI Structural Journal 94(3) (1997) 304-314.

684 [39] M.N. Hadi, Q.S. Khan, M.N. Sheikh, Axial and flexural behavior of unreinforced and FRP bar reinforced circular concrete filled FRP tube columns, Construction and Building Materials 122 (2016) 43-53.

[40] N. Banthia, J.-F. Trottier, Concrete reinforced with deformed steel fibers, part I: bond-slip mechanisms, ACI Materials Journal-American Concrete Institute 91(5) (1994) 435-446.

[41] I. Markovic, High-performance hybrid-fibre concrete-development and utilisation. Technische Universität Delft, Ph. D. thesis, 2006.

691

[42] N. Banthia, J.-F. Trottier, Concrete Reinforced with Deformed Steel Fibers--Part II: Toughness 
698

699

700

701

702

List of Tables

703

1 RPC mixture constituents.

.29

704

2 The main test matrix.

705 30

706

3 Results of specimens tested under concentric loading.

$707 \quad 31$

708

4 Results of specimens tested under eccentric loading.

709 32

710

5 Results of specimens tested under flexural loading.

711 33

712

6 The ultimate loads and moments of the tested specimens. 34

713

714

715

716

717

718

719 
Table 1. RPC mixture constituents

\begin{tabular}{lcc}
\hline Constituent & Quantity & Unit \\
\hline Portland cement & 955 & $\mathrm{~kg} / \mathrm{m}^{3}$ \\
Densified amorphous silica fume & 229 & $\mathrm{~kg} / \mathrm{m}^{3}$ \\
Natural fine sand (particles size $<600 \mu \mathrm{m})$ & 974 & $\mathrm{~kg} / \mathrm{m}^{3}$ \\
Silica flour (Grade 200) & 10 & $\mathrm{~kg} / \mathrm{m}^{3}$ \\
Water reducer and retarder & 52.6 & $\mathrm{~L} / \mathrm{m}^{3}$ \\
Water / binder & 0.133 & - \\
\hline
\end{tabular}


Table 2. The main test matrix.

\begin{tabular}{|c|c|c|c|c|c|}
\hline Group & Specimen & $\begin{array}{l}\text { Longitudinal } \\
\text { reinforcement }\end{array}$ & $\begin{array}{l}\text { lateral } \\
\text { reinforcement }\end{array}$ & $\begin{array}{c}\text { Steel fibre type and } \\
\text { content }\end{array}$ & Loading condition \\
\hline \multirow{4}{*}{$\mathrm{NF}$} & NF-E0 & \multirow{4}{*}{$6 \mathrm{~N} 12$} & \multirow{4}{*}{ R10@40 mm } & \multirow[t]{4}{*}{ 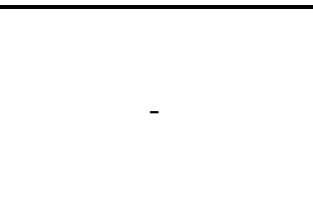 } & Concentric \\
\hline & NF-E25 & & & & Eccentric at $25 \mathrm{~mm}$ \\
\hline & NF-E50 & & & & Eccentric at $50 \mathrm{~mm}$ \\
\hline & NF-PB & & & & Flexural \\
\hline \multirow{4}{*}{ MF } & MF-E0 & \multirow{4}{*}{$6 \mathrm{~N} 12$} & \multirow{4}{*}{ R10@40 mm } & \multirow{4}{*}{$4 \% \mathrm{MF}$} & Concentric \\
\hline & MF-E25 & & & & Eccentric at $25 \mathrm{~mm}$ \\
\hline & MF-E50 & & & & Eccentric at $50 \mathrm{~mm}$ \\
\hline & MF-PB & & & & Flexural \\
\hline \multirow{4}{*}{ DF } & DF-E0 & \multirow{4}{*}{$6 \mathrm{~N} 12$} & \multirow{4}{*}{ R10@40 mm } & \multirow{4}{*}{$2 \% \mathrm{DF}$} & Concentric \\
\hline & DF-E25 & & & & Eccentric at $25 \mathrm{~mm}$ \\
\hline & DF-E50 & & & & Eccentric at $50 \mathrm{~mm}$ \\
\hline & DF-PB & & & & Flexural \\
\hline \multirow{3}{*}{ WF } & WF-E0 & \multirow{3}{*}{$6 \mathrm{~N} 12$} & \multirow{3}{*}{ R10@40 mm } & \multirow{3}{*}{$3 \% \mathrm{WF}$} & Concentric \\
\hline & WF-E25 & & & & Eccentric at $25 \mathrm{~mm}$ \\
\hline & WF-E50 & & & & Eccentric at $50 \mathrm{~mm}$ \\
\hline
\end{tabular}




\begin{tabular}{lllll}
\hline & WF-PB & & Flexural \\
& & & \\
& WHF-E0 & & & Concentric \\
WHF & WHF-E25 & & & Eccentric at $25 \mathrm{~mm}$ \\
& WHF-E50 & $6 \mathrm{~N} 12$ & R10@ $40 \mathrm{~mm}$ & $1 \% \mathrm{MF}, 0.5 \% \mathrm{DF}$ and \\
WHF-PB & & & $1.5 \% \mathrm{WF}$ & $\begin{array}{l}\text { Eccentric at } 50 \mathrm{~mm} \\
\text { Flexural }\end{array}$ \\
\hline
\end{tabular}


757

758

Table 3. Results of specimens tested under concentric loading.

\begin{tabular}{lccccc}
\hline Specimen & NF-E0 & MF-E0 & DF-E0 & WF-E0 & WHF-E0 \\
\hline Yield load (kN) & 3168 & 4279 & 3486 & 3849 & 3910 \\
$\begin{array}{l}\text { Corresponding deformation to yield load } \\
\text { (mm) }\end{array}$ & 4.4 & 5.5 & 4.7 & 4.9 & 5.0 \\
Ultimate load (kN) & 3304 & 4373 & 3607 & 4062 & 4066 \\
Corresponding deformation to ultimate & 4.6 & 5.7 & 4.9 & 5.3 & 5.6 \\
load (mm) & & & & & \\
Post ultimate deformation at $85 \%$ post & 4.7 & 6.4 & 5.1 & 6.9 & 7.3 \\
ultimate load (mm) & & & & & \\
Energy absorption & 1.1 & 1.3 & 1.2 & 1.8 & 1.9
\end{tabular}

759

760

761 
Table 4. Results of specimens tested under eccentric loading.

\begin{tabular}{|c|c|c|c|c|c|c|c|c|c|c|}
\hline \multirow[t]{2}{*}{ Specimen } & \multicolumn{5}{|c|}{ Tested under $25 \mathrm{~mm}$ eccentricity } & \multicolumn{5}{|c|}{ Tested under $50 \mathrm{~mm}$ eccentricity } \\
\hline & NF-E25 & MF-E25 & DF-E25 & WF-E25 & WHF-E25 & NF-E50 & MF-E50 & DF-E50 & WF-E50 & WHF-E50 \\
\hline Yield load (kN) & 2111 & 2763 & 2178 & 2383 & 2413 & 1285 & 1626 & 1368 & 1545 & 1441 \\
\hline Corresponding deformation to yield & 3.7 & 4.5 & 3.9 & 4.2 & 4.1 & 5.8 & 7.3 & 6.2 & 7.3 & 7.1 \\
\hline \multicolumn{11}{|l|}{ load (mm) } \\
\hline Ultimate load (kN) & 2194 & 2835 & 2246 & 2496 & 2531 & 1327 & 1711 & 1414 & 1576 & 1515 \\
\hline Corresponding deformation to & 3.9 & 4.7 & 4.0 & 4.5 & 4.3 & 6.0 & 7.8 & 6.5 & 7.5 & 7.4 \\
\hline \multicolumn{11}{|l|}{ ultimate load (mm) } \\
\hline Post ultimate deformation at $85 \%$ post & 3.9 & 5.3 & 4.0 & 5.3 & 5.2 & 6.0 & 9.2 & 6.5 & 9.4 & 9.2 \\
\hline \multicolumn{11}{|l|}{ ultimate load (mm) } \\
\hline Lateral deformation (mm) & 2.1 & 2.8 & 2.7 & 2.9 & 2.8 & 3.7 & 4.2 & 3.9 & 4.1 & 3.9 \\
\hline Energy absorption & 1.1 & 1.3 & 1.1 & 1.5 & 1.5 & 1.1 & 1.5 & 1.1 & 1.5 & 1.5 \\
\hline
\end{tabular}


Table 5. Results of specimens tested under flexural loading.

\begin{tabular}{lccccc}
\hline Specimen & NF-PB & MF-PB & DF-PB & WF-PB & WHF-PB \\
\hline Yield load (kN) & 307 & 351 & 345 & 358 & 335 \\
Corresponding deflection to yield load at & 4.3 & 5.2 & 5.4 & 6.2 & 4.6 \\
$\begin{array}{l}\text { midspan (mm) } \\
\text { Ultimate load (kN) }\end{array}$ & 356 & 393 & 379 & 403 & 389 \\
Corresponding deflection to ultimate load at & 6.5 & 7.8 & 7.6 & 8.0 & 7.6 \\
midspan (mm) & & & & & \\
Post ultimate deflection at 85\% post ultimate & 6.6 & 26.3 & 23.2 & 41.2 & 30.2 \\
load (mm) & & & & & 11.2 \\
Energy absorption & 2.0 & 8.3 & 7.0 & 11.6 & \\
\hline
\end{tabular}

770

771

772

773

774

775

776

777

778

779

780

781

782 
785

786

Table 6. The ultimate loads and moments of the tested specimens.

\begin{tabular}{|c|c|c|c|c|c|}
\hline \multirow[t]{2}{*}{ Group } & \multirow[t]{2}{*}{ Specimen } & \multirow{2}{*}{$\begin{array}{l}\text { Ultimate } \\
\text { load } \\
\mathrm{P}_{\mathrm{u}} \\
(\mathrm{kN}) \\
\end{array}$} & \multirow{2}{*}{$\begin{array}{l}\text { Lateral deformation at } \\
\mathrm{P}_{\mathrm{u}} \\
\delta_{\text {lateral }} \\
(\mathrm{mm})\end{array}$} & \multirow{2}{*}{$\begin{array}{c}\text { Midspan deflection } \\
\text { at } \mathrm{P}_{\mathrm{u}} \\
\\
\Delta_{\text {midspan }} \\
(\mathrm{mm})\end{array}$} & \multirow{2}{*}{$\begin{array}{c}\text { Ultimate } \\
\text { moment } \\
\mathrm{M}_{\mathrm{u}} \\
(\mathrm{kN} . \mathrm{m}) \\
\end{array}$} \\
\hline & & & & & \\
\hline \multirow{4}{*}{$\mathrm{NF}$} & NF-E0 & 3304 & - & - & 0 \\
\hline & NF-E25 & 2194 & 2.1 & - & 59 \\
\hline & NF-E50 & 1327 & 3.7 & - & 71 \\
\hline & NF-PB & 356 & - & 6.5 & 41 \\
\hline \multirow{4}{*}{$\mathrm{MF}$} & MF-E0 & 4373 & - & - & 0 \\
\hline & MF-E25 & 2835 & 2.8 & - & 78 \\
\hline & MF-E50 & 1711 & 4.2 & - & 92 \\
\hline & MF-PB & 393 & - & 7.8 & 44 \\
\hline \multirow{4}{*}{ DF } & DF-E0 & 3607 & - & - & 0 \\
\hline & DF-E25 & 2246 & 2.7 & - & 62 \\
\hline & DF-E50 & 1414 & 3.9 & - & 76 \\
\hline & DF-PB & 379 & - & 7.6 & 44 \\
\hline \multirow{4}{*}{ WF } & WF - E0 & 4062 & - & - & 0 \\
\hline & WF - E25 & 2496 & 2.9 & - & 69 \\
\hline & WF - E50 & 1576 & 4.1 & - & 85 \\
\hline & $\mathrm{WF}-\mathrm{PB}$ & 403 & - & 8.0 & 47 \\
\hline \multirow{4}{*}{ WHF } & WHF - E0 & 4066 & - & - & 0 \\
\hline & WHF - E25 & 2531 & 2.8 & - & 70 \\
\hline & WHF - E50 & 1515 & 3.9 & - & 81 \\
\hline & WHF - PB & 389 & - & 7.6 & 45 \\
\hline
\end{tabular}




\section{List of Figures}

791 1. The WF measurements of the diameters and the range of fibre lengths

792

793

794

795

796

797

798

799

800

801

802

803

804

805

806

807

808

809

810

811

812

814

815

813 11. The experimental $(P-M)$ interaction diagrams of the tested specimens. .36

2. The steel fibres used: (a) Micro steel fibre (MF); (b) Deformed steel fibre (DF); (c) Waste steel

fibre (WF).

3. Dimensions

of specimens

and

reinforcement

details 38

4. The fabrication of specimens: (a) Assembling steel reinforcement frame; (b) Longitudinal steel bars positioning; (c) Steel reinforcement frame; (d) Specimen formwork; (e) Cast specimens.

5. The compression testing machine equipment: (a) Specimen HF-E0 concentrically loaded; (b) Specimen WHF-E25 eccentrically loaded; (c) Loading head details.......40

6. Specimen WF-PB under flexural loading

7. Modes

of

failure

of

the

tested

specimens . .42

8. Close-view of the tested specimens under flexural loading.

9. Calculation of energy absorption of the tested specimens

10. The load-deformation curves of the specimens: (a) concentrically loaded; (b) eccentrically loaded at $25 \mathrm{~mm}$; (c) eccentrically loaded at $50 \mathrm{~mm}$; (d) flexural loading. . .45 .48 
817

818

819

Page $\mathbf{3 7}$ of $\mathbf{5 0}$ 


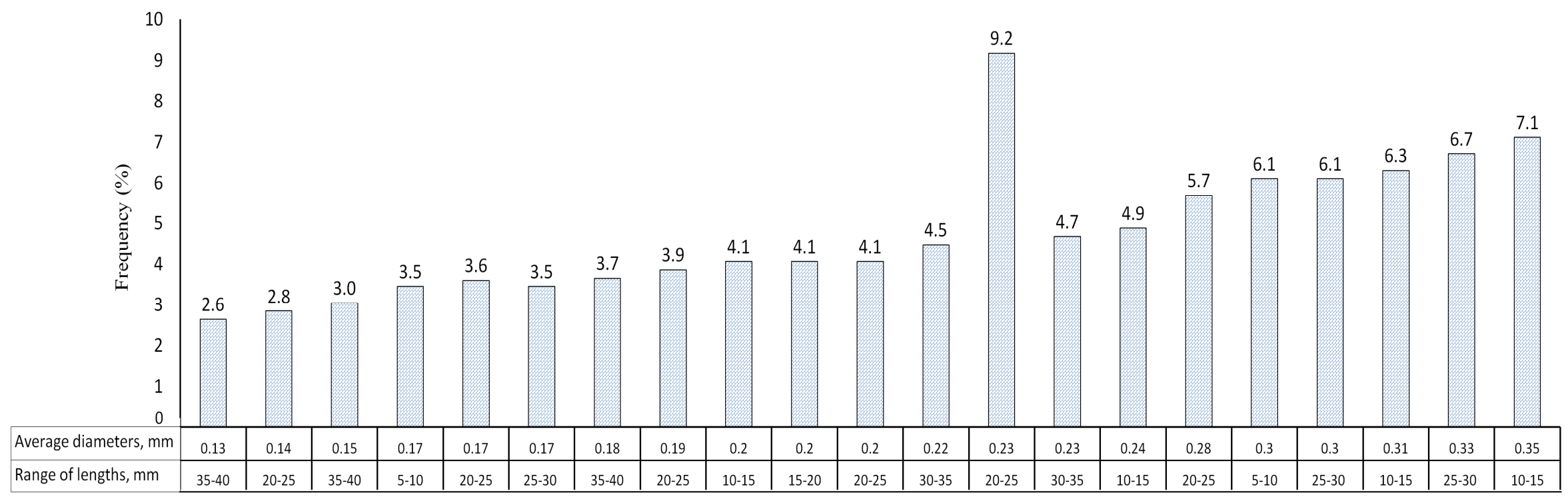

Figure 1. The WF measurements of the diameters and the range of fibre lengths. 


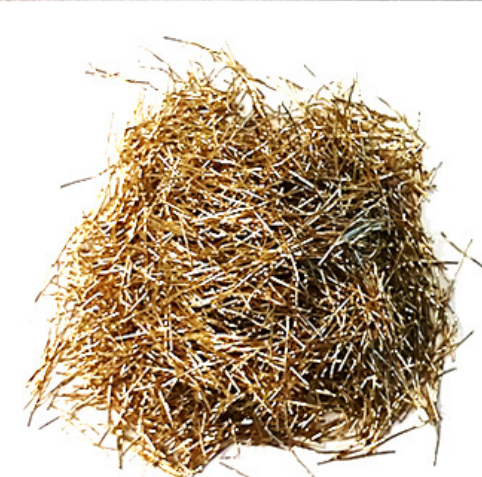

(a)

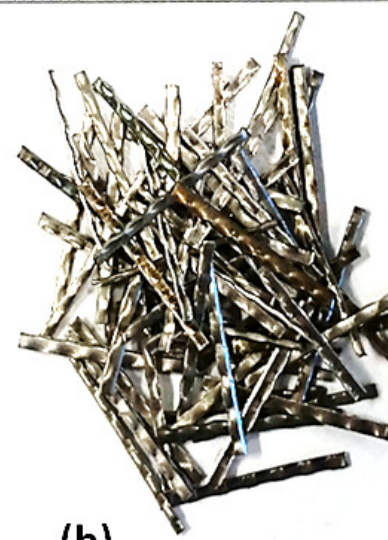

(b)

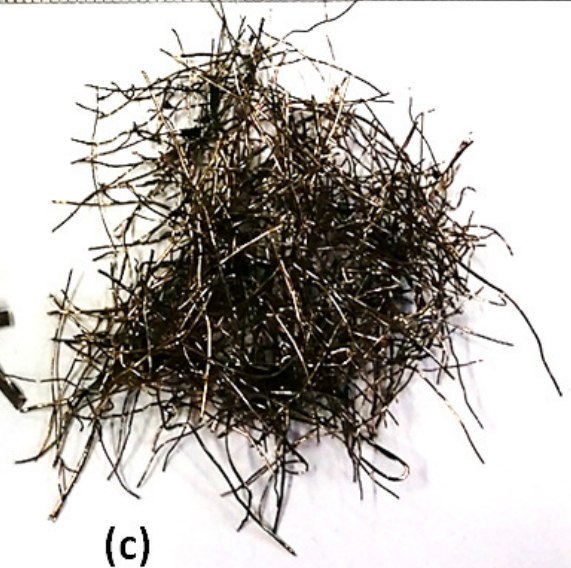

(c)
834

835 836

837

838

839

840

841

842

843

844 fibre (DF); (c) Waste steel fibre (WF).

Figure 2. The steel fibres used: (a) Micro straight steel fibre (MF); (b) Macro deformed steel 

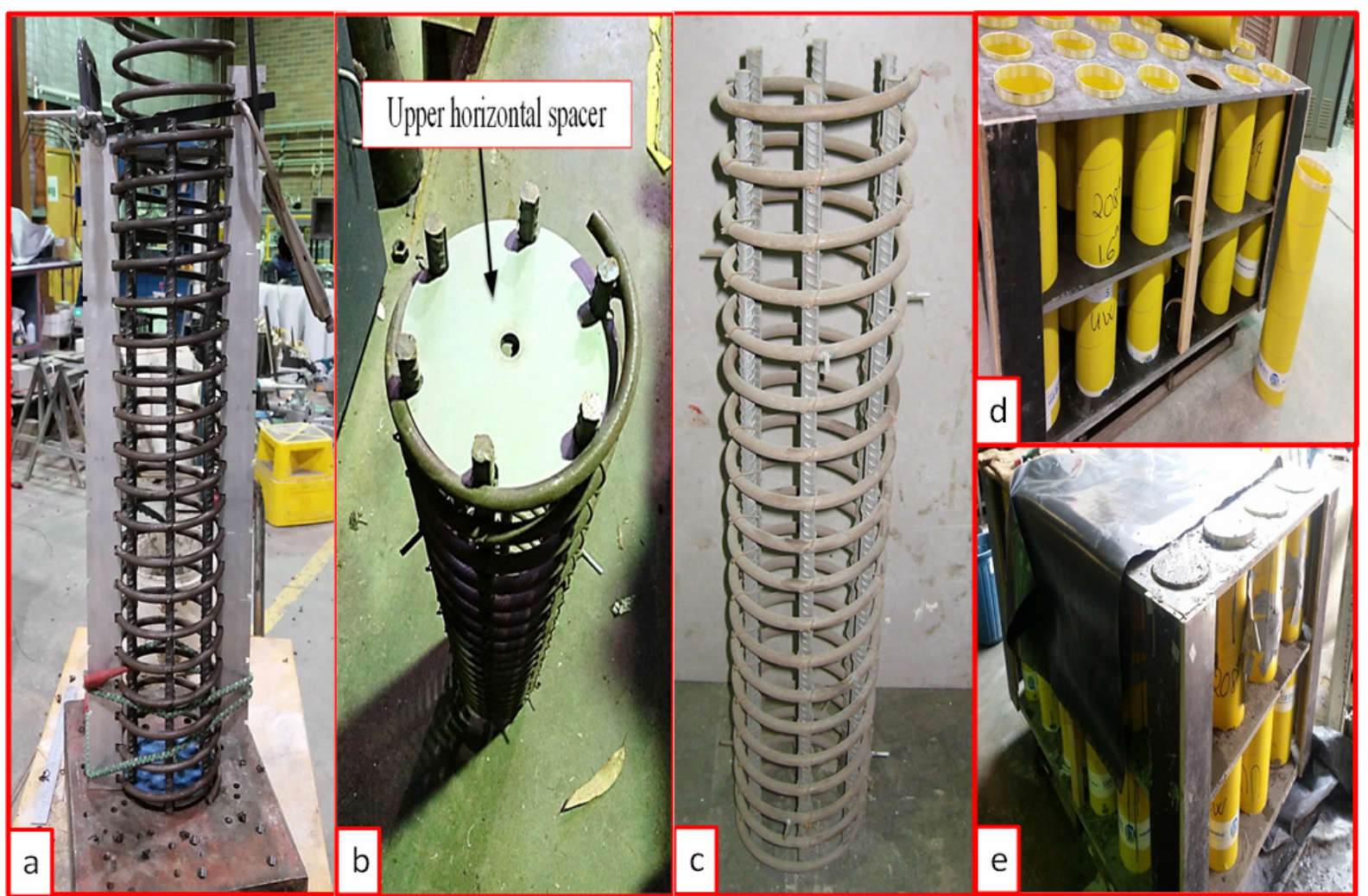

852

Figure 3. The fabrication of specimens: (a) Assembling steel reinforcement frame; (b)

853

Longitudinal steel bars positioning; (c) Steel reinforcement frame; (d) Specimen formwork;

(e) Cast specimens. 

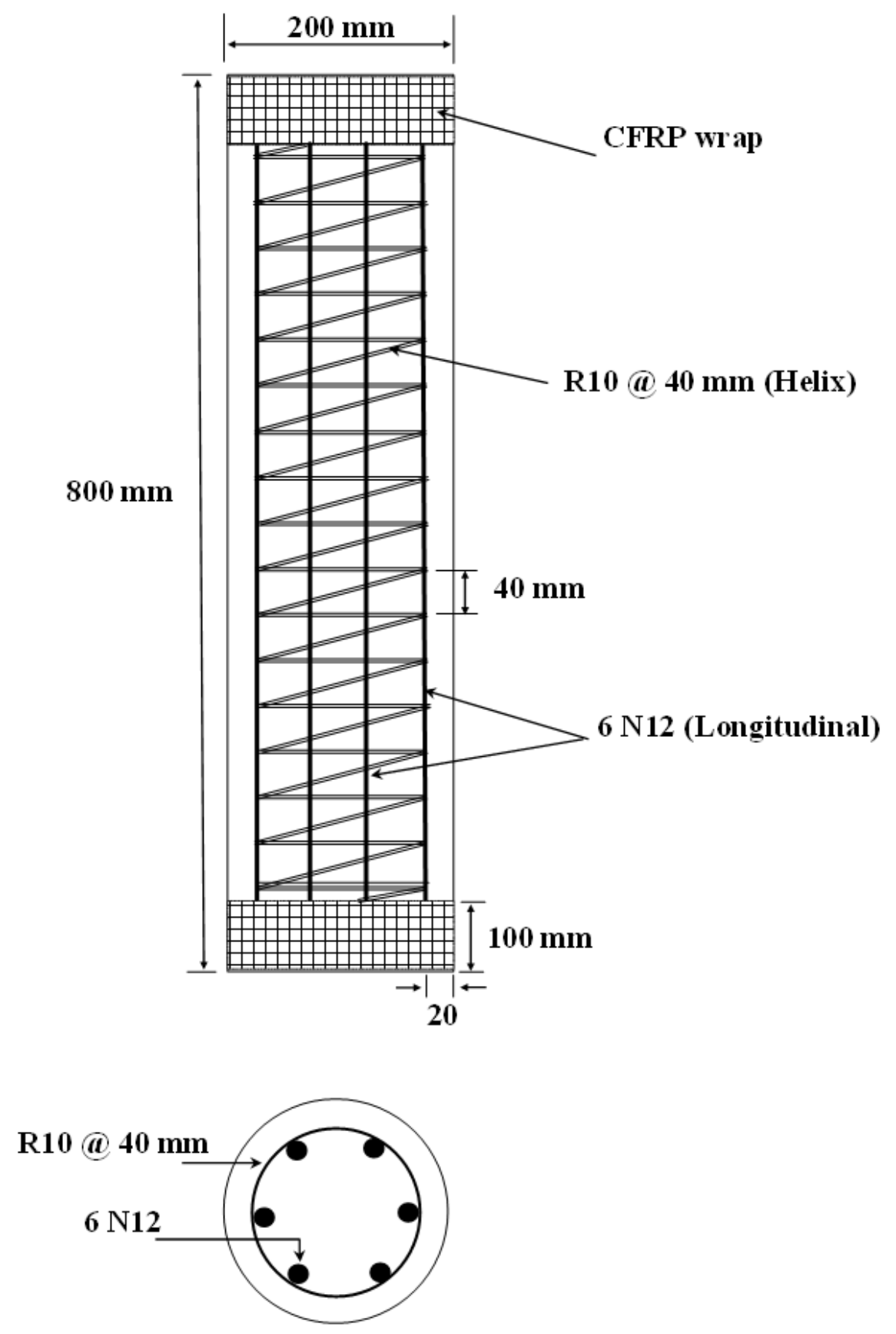


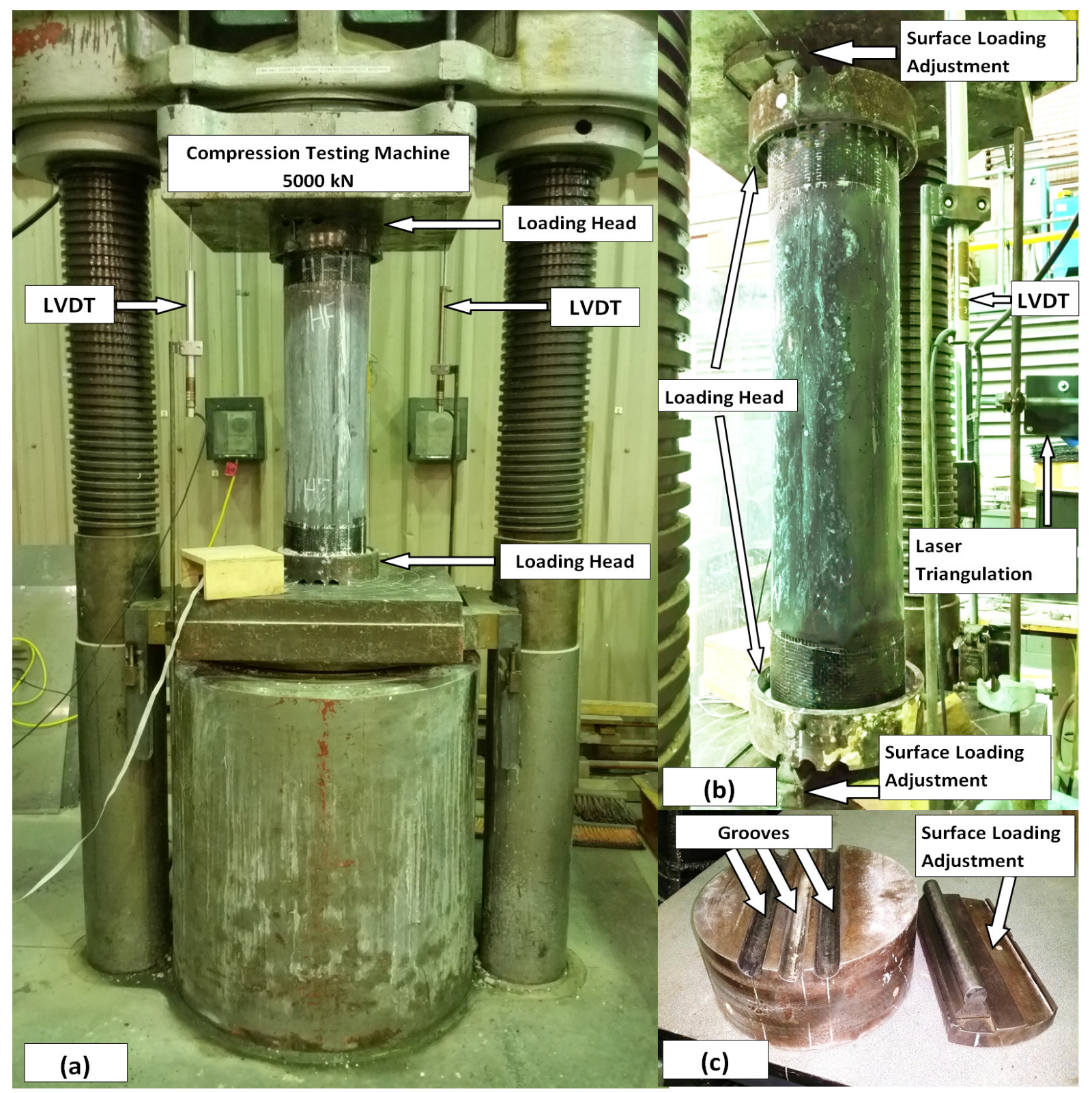

872 Figure 5. The compression testing machine equipment: (a) Specimen HF-E0 concentrically loaded; (b) Specimen WHF-E25 eccentrically loaded; (c) Loading head details. 


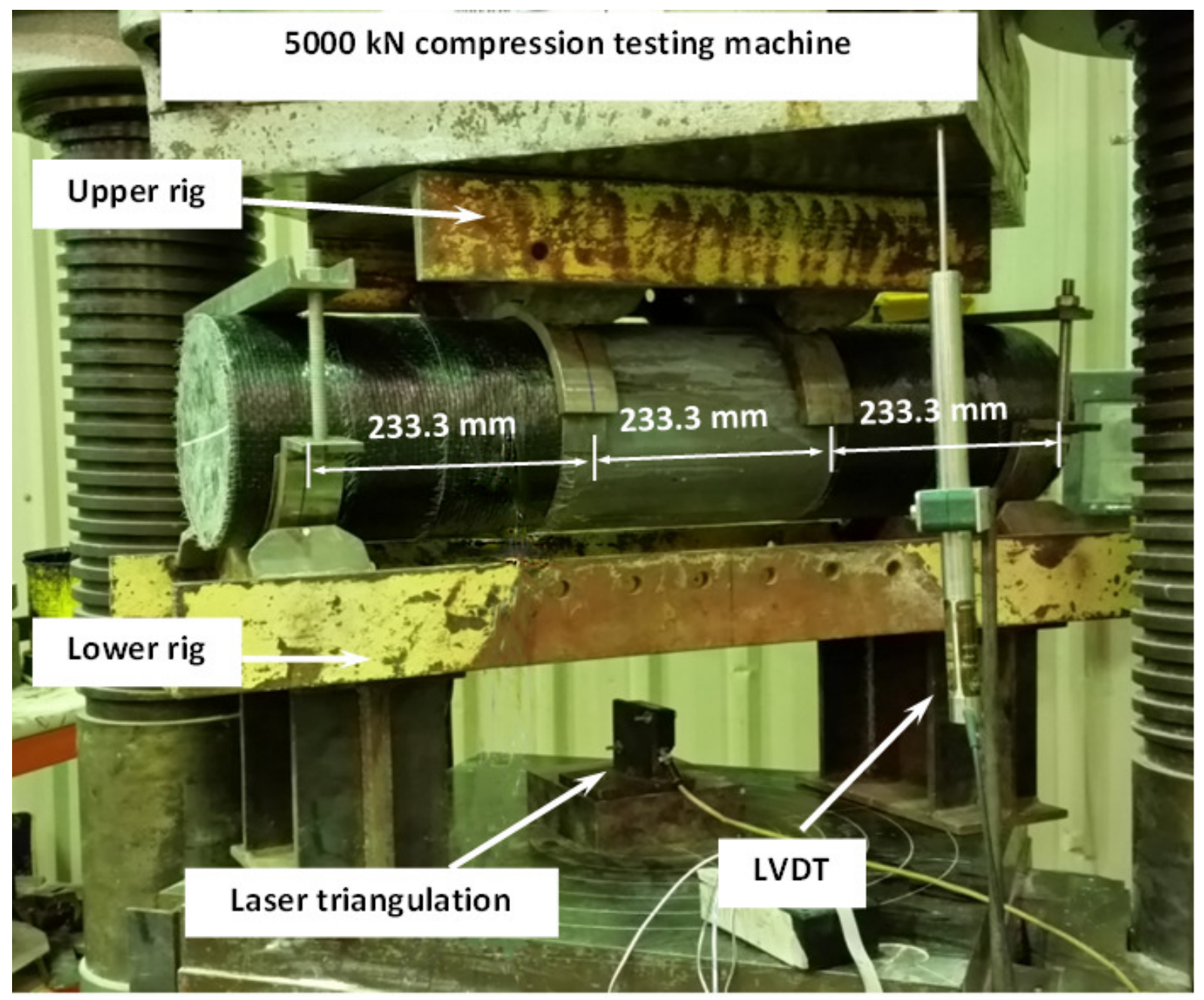

Figure 6. The flexural load test equipment during testing Specimen WF-PB. 

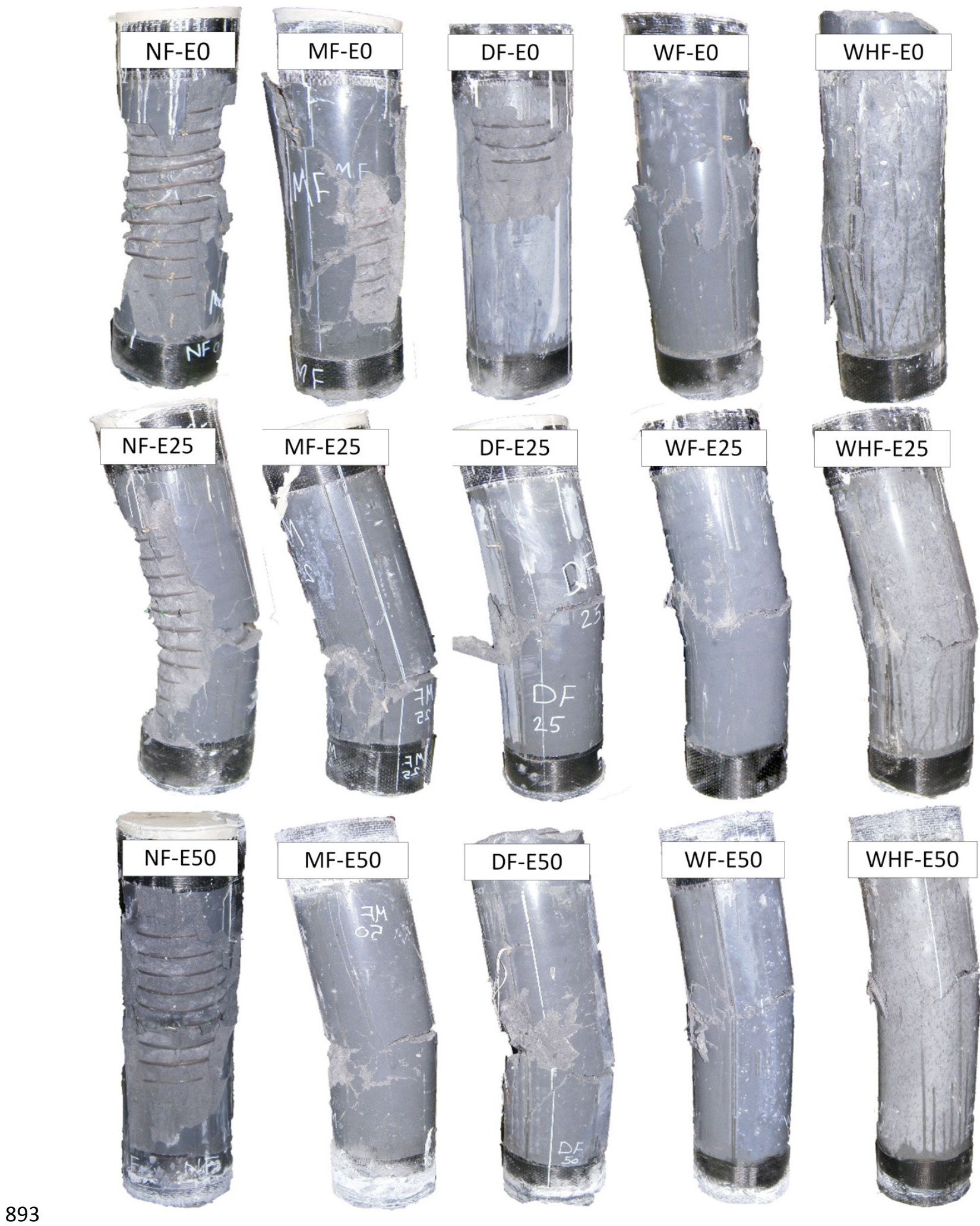

Figure 7. Modes of failure of the tested specimens. 

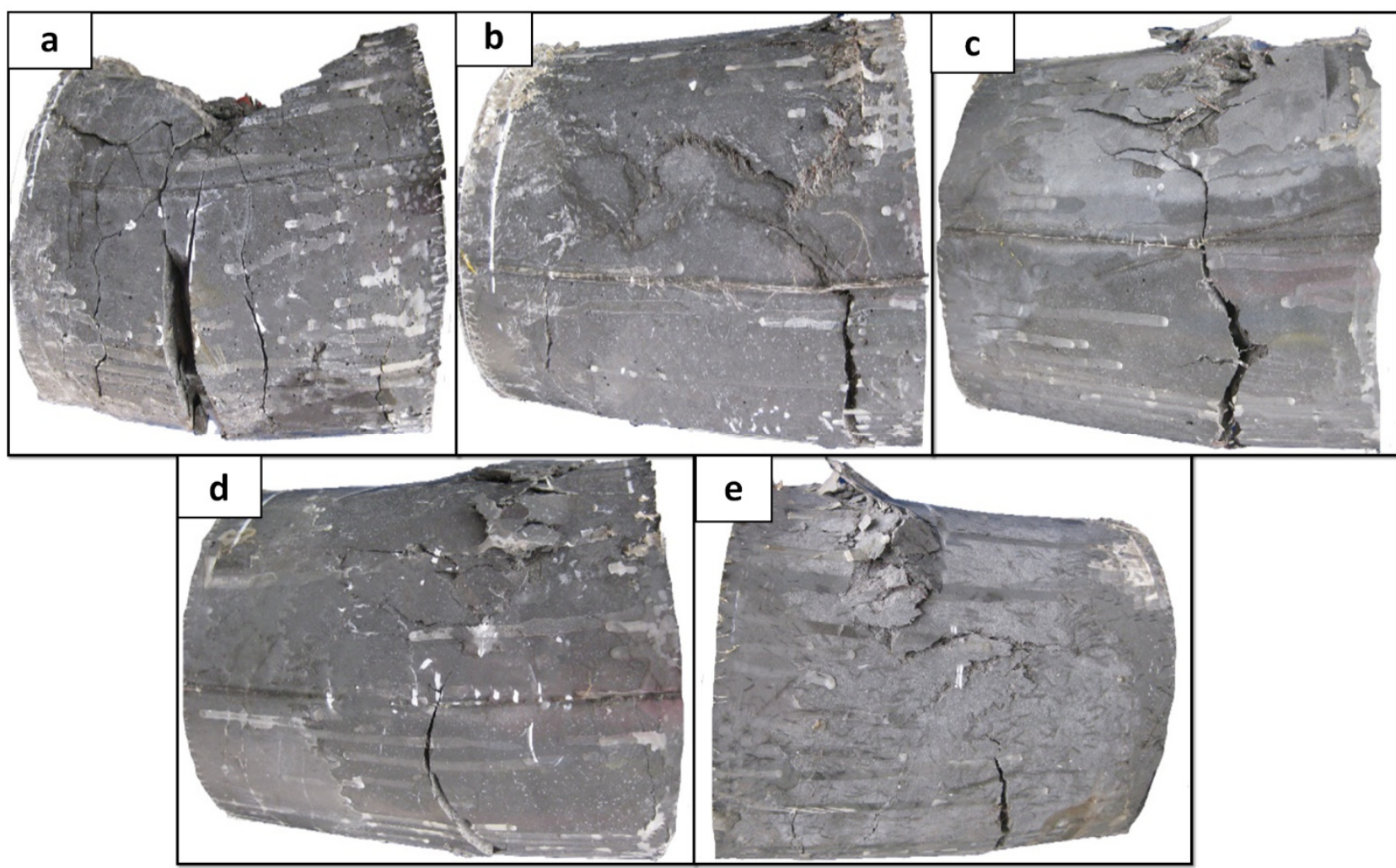

903

Figure 8. Close-view of the specimens tested under flexural loading: a) Specimens NF-PB, b)

904 Specimens MF-PB, c) Specimens DF-PB, d) Specimens WF-PB and e) Specimens WHF-PB.

905

906

907

908

909 


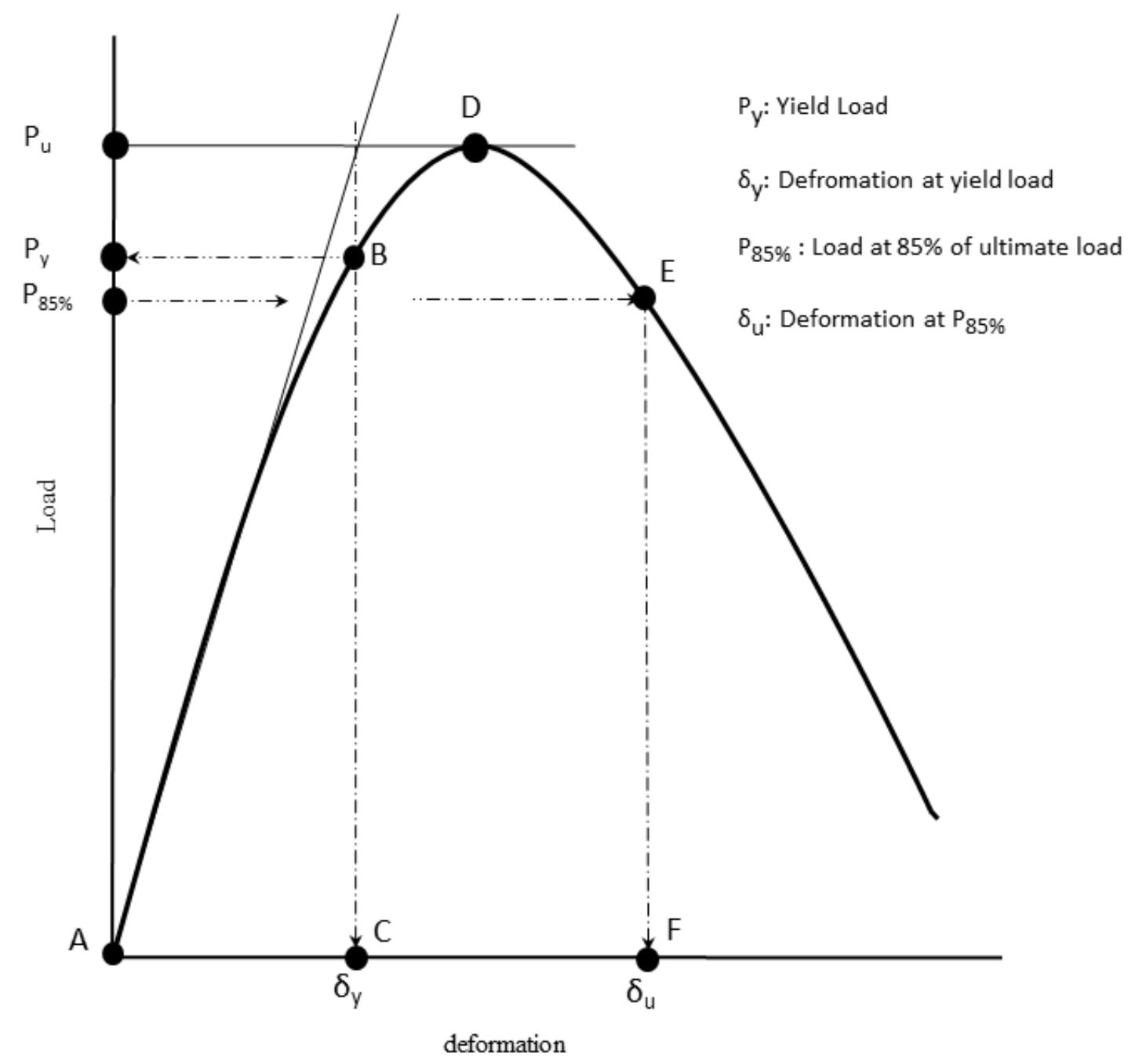




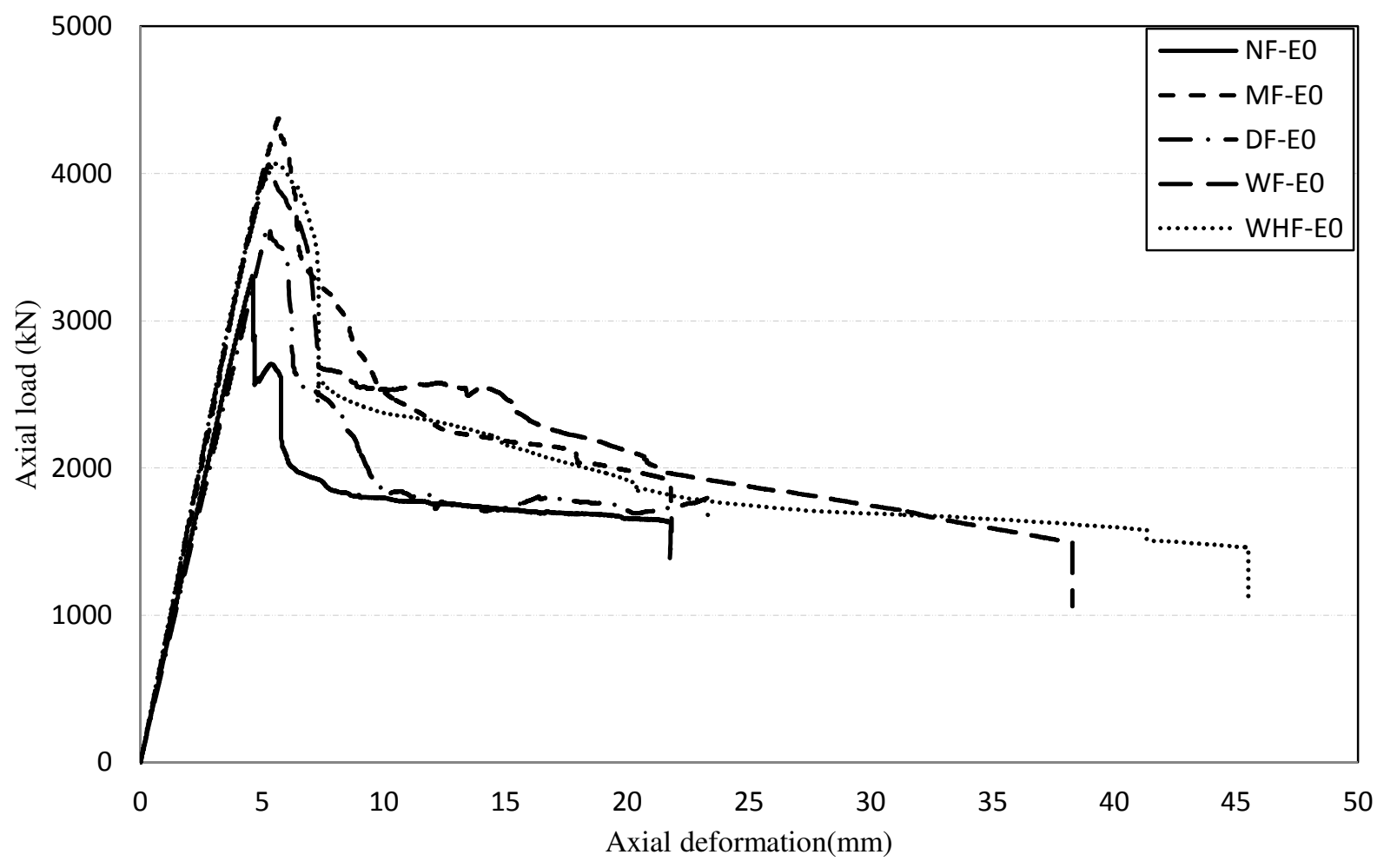

923

(a)

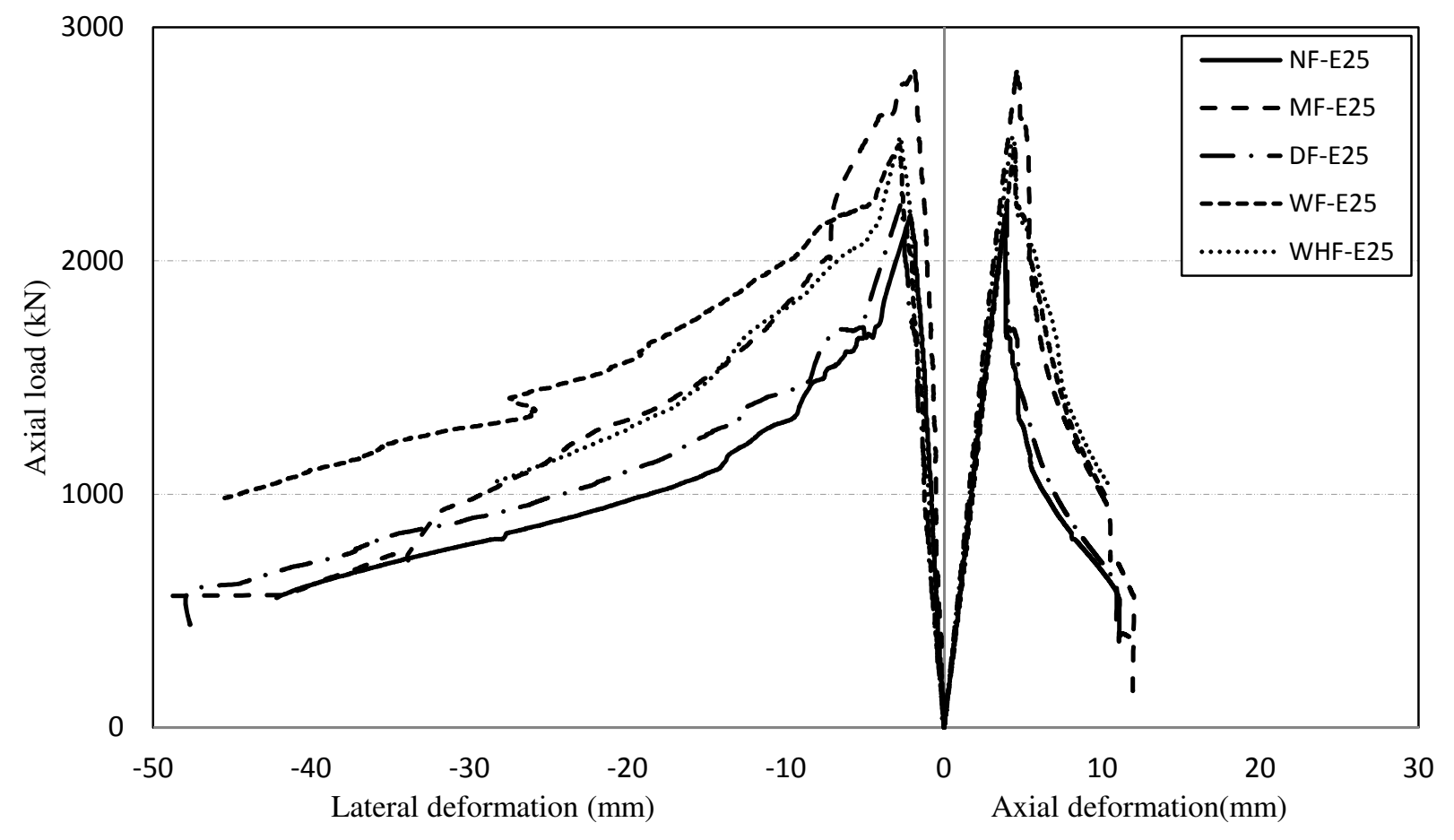

(b) 
930

931

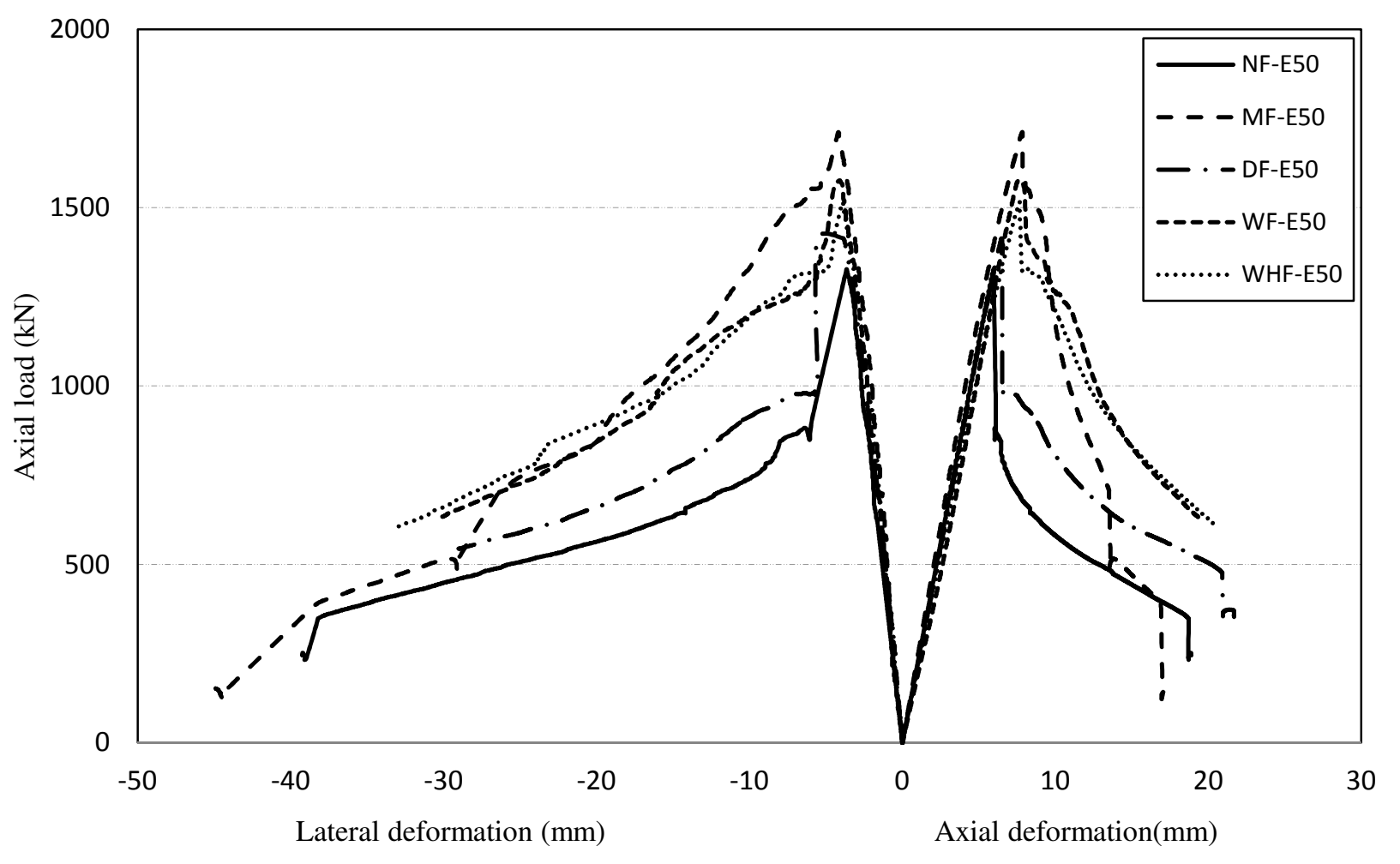

932

(c)

934

935

936

937

938

939

940

941

942 


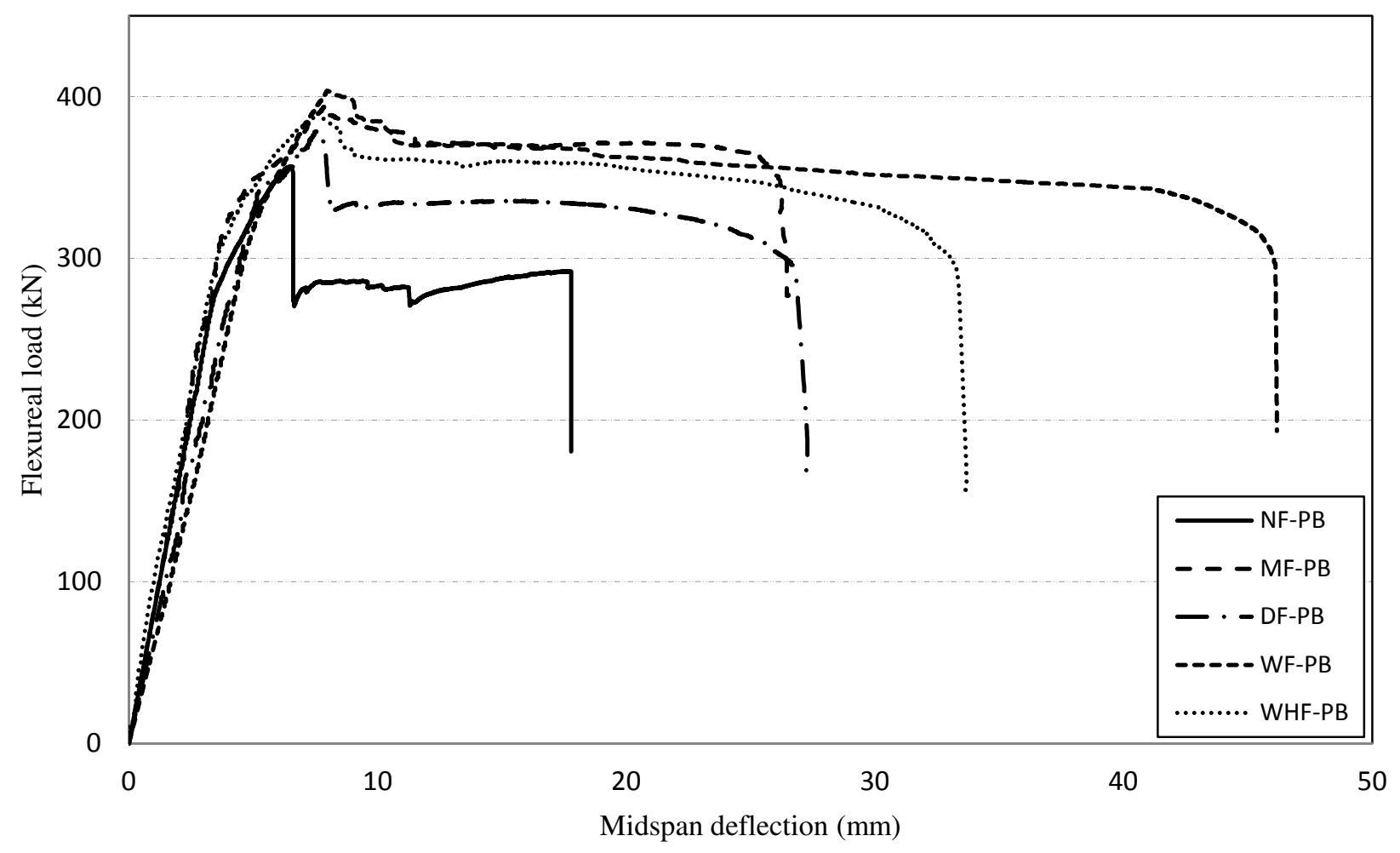

(d)

Figure 10. The load-deformation curves of the specimens tested under: (a) concentric 


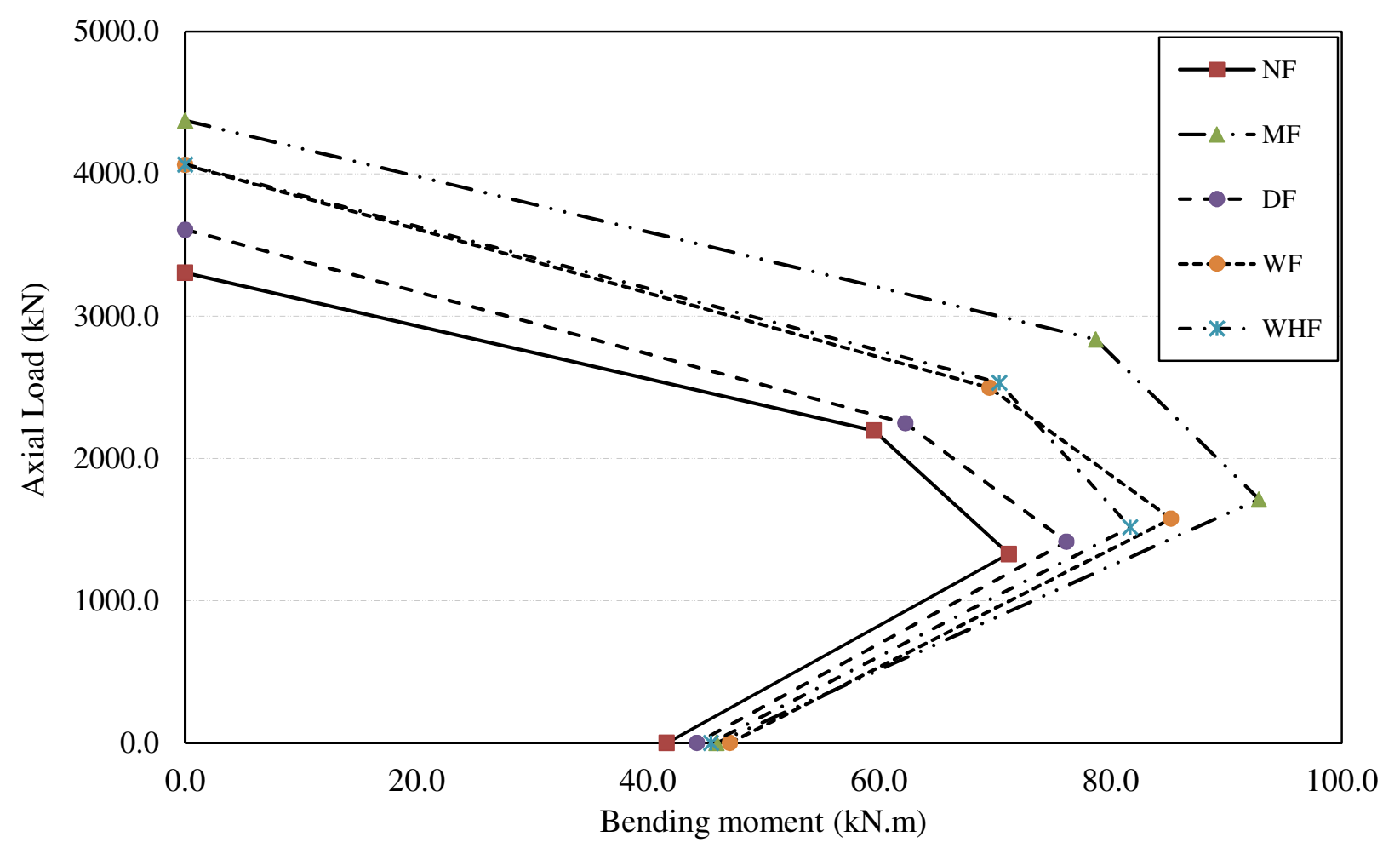

963

Figure 11. The experimental $(P-M)$ interaction diagram of tested specimens. 